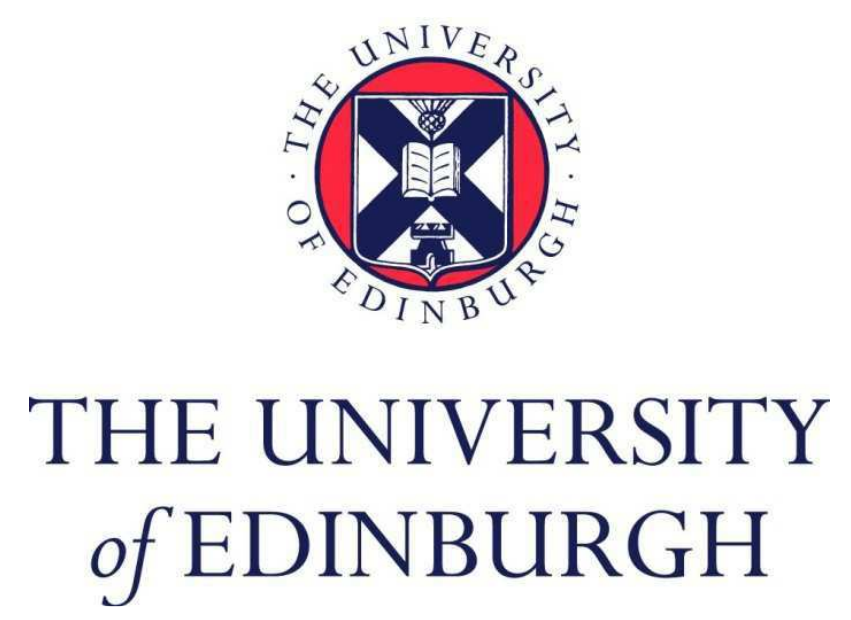

This thesis has been submitted in fulfilment of the requirements for a postgraduate degree (e.g. PhD, MPhil, DClinPsychol) at the University of Edinburgh. Please note the following terms and conditions of use:

This work is protected by copyright and other intellectual property rights, which are retained by the thesis author, unless otherwise stated.

A copy can be downloaded for personal non-commercial research or study, without prior permission or charge.

This thesis cannot be reproduced or quoted extensively from without first obtaining permission in writing from the author.

The content must not be changed in any way or sold commercially in any format or medium without the formal permission of the author.

When referring to this work, full bibliographic details including the author, title, awarding institution and date of the thesis must be given. 


\title{
Three Essays in Microeconomic Theory
}

\author{
Man Si
}

\section{PhD Economics}

The University of Edinburgh

2014 


\section{Contents}

Abstract .............................. 1

1 Intrafamily Bargaining and Love 3

1.1 Introduction . . . . . . . . . . . . . . . . . 3

1.2 Related Literature . . . . . . . . . . . . . . . . . 4

1.3 The Model . . . . . . . . . . . . . . . . . . . . . 7

1.3.1 Utility Function . . . . . . . . . . . . . . 7

1.3.2 Stage Game . . . . . . . . . . . . . . . . . 8

1.3.3 Game Structure . . . . . . . . . . . . . . . . 10

1.3.4 Equilibrium ................... . . . 10

1.4 Outlook: Potential for Testing . . . . . . . . . . . . 18

1.5 Conclusions ........................... 20

2 Perception of Technology and Technological Progress under Extractive Institutions $\quad 22$

2.1 Introduction . . . . . . . . . . . . . . . . . . . . 22

2.2 Related Literature . . . . . . . . . . . . . . . . . . 23

2.3 Model Setup . . . . . . . . . . . . . . . . . . . 27 
2.4 Equilibrium Analysis . . . . . . . . . . . . . . . . . 35

2.4.1 Geometric Growth $(\theta>\hat{\theta}) \ldots \ldots . \ldots 35$

2.4.2 Arithmetic Growth $(\theta \leq \hat{\theta}) \ldots \ldots . \ldots . \ldots 39$

2.5 Extension A: inclusive institutions as a commitment device to a fixed tax rate . . . . . . . . . . . . . . . . . 41

2.5.1 Geometric Growth Regime $(\theta>\hat{\theta}) \ldots \ldots 41$

2.5.2 Arithmetic Growth Regime $(\theta \leq \hat{\theta}) \ldots . . . . . . .443$

2.6 Extension B: Uncertainty over the Nature of Technology . . . . 45

2.7 Discussion . . . . . . . . . . . . . . . . . . . . . . . . . . . . 48

3 A critical literature review of the Property Rights Theory of the Firm and the communication of Unprotected Information $\begin{array}{ll}\text { Assets } & 50\end{array}$

3.1 Introduction . . . . . . . . . . . . . . . . . 50

3.2 Literature review . . . . . . . . . . . . . . . . . . 51

3.2.1 The Property Rights Theory of the Firm . . . . . . . . . 51

3.2.2 A single biased agent with soft private information . . . 54

3.2.3 Multiple agents and horizontal versus vertical communication .................... 57

3.2.4 Endogenous managerial bias . . . . . . . . . . . 66

3.2.5 Career concerns induced communication equilibria . . . . 72

3.3 Discussion of future avenues for research . . . . . . . . . . 74

3.4 Conclusions . . . . . . . . . . . . . . . . . . . 77

References . . . . . . . . . . . . . . . . 78 
Appendices 


\section{Declaration}

The candidate hereby declares that

- the thesis has been composed by the candidate, and

- that the work is the candidate's own, and

- that the work has not been submitted for any other degree or professional qualification except as specified.

signed 


\begin{abstract}
Chapter 1: Intrafamily Bargaining and Love

Popular culture and common wisdom testify that the way partners in a relationship feel for one another very much depends on how they treat each other. This paper posits the hypothesis that altruism or love in a relationship is endogenous to the actions of the partners and studies how this influences allocations and efficiency in a bargaining model of household decision-making. The main results are that agents treat their partner in a kinder way than without endogenously evolving love, this leads to more equitable allocations in household decision making and greater intertemporal efficiency. There are two mechanisms at work: agents treat their partner nicely to avoid retribution by a less loving partner in the future; and they treat the partner nicely so that the kind reciprocal behavior raises their own love towards the partner, which lets them enjoy higher utility.

As to love, two interpretations emerge: love is a commitment device by which couples can implement Pareto superior allocations; and love is an investment good in the sense that costly nice behavior towards the partner today may ensure higher levels of trust and efficiency in the future.

This chapter has been published as Si [2014].

Chapter 2: Perception of Technology and Technological Progress under Extractive Institutions

This paper explores the impact of different perceptions of the nature of technology - whether it may grow in an arithmetic or geometric fashion - on the choices of an elite that lives on extracting resources from the productive populace. We show that slow potential growth destroys the credibility of inclusive institutions that the elite may consider in order to foster growth whereas these can and will be implemented if populace and elite believe in fast growth.

Belief in the potential of technological growth leads to growth-friendly policies under both extractive and inclusive institutions and, as history progresses, the true nature of technology reveals itself and this belief spreads.
\end{abstract}


Chapter 3: A critical literature review of the Property Rights Theory of the Firm and the communication of Unprotected Information Assets

This paper reviews the literature centred on the question of what kind of settings facilitate the transmission of unverifiable pieces of information that reside with an agent whose incentives are not well aligned with an agent for whom this piece of information is useful. The question is framed within the Property Rights Theory of the Firm and its answers make extensive use of the modelling device of Cheap Talk. The main findings are that communication leads to costly distortions and the efforts to decrease bias and information loss may trigger major revisions to the structure of incentive systems and the allocation of decision-rights. The paper argues that the literature has so far failed to properly examine the question of property rights of information and is therefore focused on niche applications. 


\section{Chapter 1}

\section{Intrafamily Bargaining and Love}

\subsection{Introduction}

Any cursory look at popular culture, from any age, suggests that love takes center stage at least at some point in the life of most people.

And yet the love between two people has received scant interest from economists. When it appears, it is usually either invoked to justify altruistic feelings within a household as in Nordblom [2004] or to describe the emotional benefit two agents gain when matched in a marriage as in Konrad and Lommerud [2008]; while in Hess [2004] love is a public good in marriage that follows an exogenous process.

This paper takes a different view: while initial love or suitability upon the first meeting may be viewed as exogenous, love/altruism in a relationship is responsive to what is happening in that relationship. In particular, the way one partner treats the other will influence the love his partner feels for him and so love co-evolves with the relationship, strengthening or deteriorating depending on the choices of the partners. In more economic terms, love is endogenous to the decision-making within the family.

The most closely related paper is Browning [2009] who explores how the fear of a drop in affection due to a 'betrayal' can help couples overcome commitment issues in their decision-making. Whereas his analysis focuses on the single decision of betrayal or no betrayal and a loss of love, I study the evolution of love 
as the spouses repeatedly interact. In so doing this paper can also be likened to Liu [2007] who looks for the optimal investment into the quality of a marriage in a dynamic setting - ignoring, however, issues of love and strategic interaction.

Following the received literature on household decision-making, I model the family as a couple who simultaneously and repeatedly decide how much of their time each should allocate to privately enjoyed leisure and to household public good production which, as indicated by the wording, benefits both members of the couple. As the allocation of work is endogenously determined, this setup can be interpreted as a stylized model of bargaining. The love an agent feels towards his partner is then assumed to be responsive to the time allocation decision of the partner.

From the Markov-perfect equilibrium I derive the steady states dependent on the parameter values and the initial state. It is then argued that agents, anticipating the endogenous change in their own and their partner's incentives due to changes in the levels of love, invest into the relationship by working more than would be optimal considering the single period setup. They may share the burden of lifting their partnership to the full love state by playing strategies that are complementary in investment.

In cases in which agents are sufficiently patient and productive in household public good production as well as face sufficiently low risks of divorce, breakup or death, the initial levels of love therefore play no role in the steady state. For the less patient, less productive, and at higher risk, which one may perhaps interpret at less suited for one another, this does not hold and initial levels of love determine the utility levels of the steady state.

\subsection{Related Literature}

In exploring a way of modeling the evolution of love in a relationship, the present paper builds on and contributes to the received literature on household decisionmaking.

In what McElroy and Horney [1981] called the "neoclassical" approach, economists have for a long time treated the decision-making within the household 
as resulting in the household behaving towards the outside world like a single individual. This was given a formal shape by Samuelson [1956] who looked for conditions under which the household acts like an individual; in doing so he posits a social welfare function which the household members agree to maximize, together with lump-sum transfers between the members ${ }^{1}$.

This unitary view of the household can also be found in parts of the work of Gary S. Becker, most explicitly in the so-called Rotten Kid Theorem, proposed in Becker [1974a] and elaborated in amongst others Bergstrom [1989], Bruce and Waldman [1990] and Johnson [1990].

Becker, however, was also among the first to explore non-unitary models of decision-making in households, foremost in his seminal paper on time allocation, Becker [1965], but also on his work on marriage, e.g. Becker [1973] $]^{2}$.

Independently from each other, Manser and Brown [1980] and McElroy and Horney [1981] developed models of household decision-making based on the conception that households can be understood as two individuals bargaining over the distribution of the gains realized by entering the household (or marriage). Manser and Brown [1980] explore different bargaining setups such as Nash bargaining, bargaining according to Kalai and Smorodinsky [1975] as well as dictatorial bargaining while the analysis of McElroy and Horney [1981] focus on Nash bargaining and work out in detail the differences in implications for observable demand between Nash bargaining households and single households. The underlying view of the household is one in which individuals may have different preferences, yet come together because there are gains from close cooperation. These may be due to differences in their productivity in household production processes ${ }^{3}$ or to the benefits of joint consumption like household public goods ${ }^{4}$.

The ensuing literature has given attention to non-cooperative aspects of household decision-making. Lundberg and Pollak [1993] define the threat point of the bargaining not by the utility in the single state but by the utility in a

\footnotetext{
${ }^{1}$ As noted by Samuelson [1956], this model does not attempt explain how decision-making within households actually takes place.

${ }^{2}$ For a discussion see Grossbard [2010].

${ }^{3}$ See e.g. Becker $[1965,1981]$ and Pollak and Wachter [1975]. A recent addition to this line of enquiry is given by Brown and Zhang [2012]

${ }^{4}$ See the discussion in Manser and Brown [1980] p. 34.
} 
non-cooperative Cournot equilibrium in which the agents do not end the marriage but make only voluntary contributions to household public goods. Other papers that apply solution concepts of non-cooperative game theory to household decision-making problems include Bragstad [1991], Lundberg and Pollak [1996] and Konrad and Lommerud [1995, 2000].

The literature has also been exploring the implications of explicitly modeling household behavior in a dynamic way; this includes for instance Ligon [2011], Konrad and Lommerud [2000], Lundberg and Pollak [2003] and Basu [2006]. Lundberg and Pollak [2003] exemplify the main point of this part of the literature; they consider a dual-earner couple deciding on the location at which to live and work which is modeled as a two stage game. If location choice influences the bargaining power of the household members in the second stage and this is foreseen in the first stage, then even Pareto optimal bargaining in the second period is not sufficient to ensure Pareto efficiency of the full game. This result is replicated in different guises across the literature: Endogenous bargaining power and limited commitment power induce inefficiency in the decision-making process of households.

Recently, Browning [2009] demonstrated that introducing love and a feeling of betrayal into the location problem discussed above may overcome this inefficiency. In particular, the advantaged spouse can choose not to exercise her increased bargaining power and she may be able to commit to this because reneging on the promise would cause the Beckerian caring, or love, of the partner to drop. This is described as the effect of betrayal and works as a commitment device because it is automatic and thus immune to renegotiation.

Approaching the problem from another angle, Dufwenberg [2002], who draws on insights of psychological games ${ }^{5}$, shows that with beliefs based on forward induction an equivalent commitment device can be provided by a feeling of guilt. Yet another angle is chosen by Cigno [2012] who shows that the institutional setup of the marriage contract can ameliorate dynamic efficiency by handing the partner whose future bargaining position is weakened the credible threat of

\footnotetext{
${ }^{5}$ The classic reference for psychological games is Geanakoplos et al. [1989]. Their approach has been adapted to fairness (including reciprocity) in normal form games by Rabin [1993]; extensions to sequential games can be found e.g. in Dufwenberg and Kirchsteiger [2004] and Falk and Fischbacher [2006]. For a recent exposition of altruistic feelings dependent on intentions see Cox et al. [2007].
} 
divorce.

The model developed in the next section builds on this last strand of literature: the evolution of love within marriage can be interpreted as the endogenous evolution of the bargaining power in the decision-making process of the household. It will be shown that it can also be interpreted as a commitment device in a similar fashion to Browning [2009].

\subsection{The Model}

\subsubsection{Utility Function}

Let the household consist of two agents, $A$ and $B$, who interact repeatedly. Agents consume leisure and a household specific public good which they produce using a constant returns to scale production function; let the level of the public good in period $t$ be denoted $G_{t}=\beta\left(w_{A, t}+w_{B, t}\right)$ where $w_{i, t}$ is the amount of work that agent $i$ puts into the production of the public good and $\beta \in\left(\frac{2}{3}, 1\right)$ is the productivity of agents in this activity. Normalizing disposable time per period to 1 lets the decision variable be $w_{i, t} \in[0,1]$ and yields leisure of $1-w_{i, t} \geq 0$. To simplify the analysis I restrict the choice of the agents to the discrete set of $w_{i, t} \in\{0,1\}$.

For his instantaneous self-regarding utility, agent $i$ values these two goods according to (where $j \neq i$ ):

$$
u_{i, t}=u\left(G_{t}, 1-w_{i, t}\right)=\beta\left(w_{i, t}+w_{j, t}\right)+\left(1-w_{i, t}\right) .
$$

He also cares about the other agent in the household and so his total instantaneous utility is given by:

$$
v_{i, t}=u_{i, t}+\alpha_{i, t} u_{j, t}
$$

where $\alpha_{i, t}$ measures his 'love' towards the other agent; note that this love is potentially time-varying. These are preferences that Becker [1974b] called "caring". $\alpha_{i, t}$ must be an element of $\{0,1\}$. Letting $\alpha_{i, t}$ only take these two particular values can be motivated by interpreting the real world equivalent of a period in the model to be measured in weeks or months rather than hours or days. In 
each period, love is thus determined by the experience one has accumulated over a longer stretch of time and it is this love that influences the decision-making for the next period. Love in this model defines a state of being and this one can argue is mostly polarised in either a loving or a not loving state.

It is standard in the literature to let these caring preferences be targeted at the instantaneous self-regarding utility of the partner rather than his total instantaneous utility or total expected utility and this is very fitting in the circumstances of this model. The setting is not one of Pareto efficient axiomatic bargaining but of non-cooperative games and so it is natural to assume that the caring towards the partner is limited to what one can directly observe or guess with high confidence, namely instantaneous self-regarding utility; loving the other love of the other person appears far-fetched.

Agents are assumed to be expected utility maximizers and thus agent $i$ in period $t$ seeks to maximize the following expression:

$$
\begin{gathered}
U_{i, t}=\sum_{\tau=t}^{\infty} \delta^{\tau-t} E_{t}\left(v_{i, \tau}\right) \\
=\sum_{\tau=t}^{\infty} \delta^{\tau-t} E_{t}\left[\left(1+\alpha_{i, \tau}\right) G_{\tau}+\left(1-w_{i, \tau}\right)+\alpha_{i, \tau}\left(1-w_{j, \tau}\right)\right] .
\end{gathered}
$$

As fixed parameters we have the time discount factor $0<\delta<1$ and the productivity of agents in household good production $\beta$. Note that the discount factor can be interpreted as a reduced form in the sense that it collapses discount factors for time preference and risk, $\delta=\delta_{\text {time }} \cdot \delta_{\text {risk }}$, where risk includes mortality and breakup or divorce. As a shorthand, I shall refer to the collapsed $\delta$ as 'patience'.

\subsubsection{Stage Game}

If $\alpha_{A, t}=\alpha_{B, t}=0$ and $\beta$ is in $\left(\frac{1}{2}, 1\right)$ the stage game is a classical prisoners' dilemma: $\beta>\frac{1}{2}$ means that the Pareto efficient outcome is for both agents to put all their time into household public good production while $\beta<1$ ensures that implementing this outcome is not the preferred strategy under any circumstance.

Non-zero levels of love change this: for an agent in love, putting all his effort 
into household public good production is the dominant strategy and so the prisoners' dilemma disappears. Less obviously, the lower bound on $\beta$ for which the Pareto optimum involves both agents working changes from $\frac{1}{2}$ to $\frac{2}{3}$. This can be verified by an inspection of the social welfare function $W_{t}=U_{t, i}+U_{t, j}$ which after rearranging can be written as:

$$
W_{t}=\left(2+\alpha_{t, i}+\alpha_{t, j}\right) \beta\left(w_{t, i}+w_{t, j}\right)+\left(1+\alpha_{t, j}\right)\left(1-w_{t, i}\right)+\left(1+\alpha_{t, i}\right)\left(1-w_{t, j}\right) .
$$

Clearly, the work leisure trade-off, from a social planner's point of view, is summarized by the marginal payoff from work in household public good production, $\left(2+\alpha_{t, i}+\alpha_{t, j}\right) \beta$, and the marginal payoff from leisure, $1+\alpha_{t, j}$ and $1+\alpha_{t, i}$, respectively.

As long as $\alpha_{t, i}=\alpha_{t, j}=\alpha_{t}$ we have that $\left(2+\alpha_{t}+\alpha_{t}\right) \beta>1+\alpha_{t}$ (so that $w_{t, i}=w_{t, j}=1$ is socially optimal) if $\beta>\frac{1}{2}$ and the reverse if $\beta<\frac{1}{2}$; this follows from the public good nature of the household good and the fact that we are looking at a household of two agents.

When the two levels of love are not the same $\alpha_{t, i} \neq \alpha_{t, j}$ then things are complicated by the fact that the agent with the higher level of love, say $i$, internalizes the self-regarding well-being of his partner more than vice-versa. This internalization gives the object of affection the characteristic of a public good and therefore the leisure consumed by better loved agent receives greater weight in the social welfare function: the marginal payoff of $j$ 's leisure increases proportionally with $\alpha_{i, t}$ while the payoff of his work increases only proportionally to $\alpha_{i, t} \beta$. In this case, $\beta>\frac{1}{2}$ is not a sufficient condition for $w_{t, i}=w_{t, j}=1$ being socially optimal.

If $\beta>\frac{2}{3}$, however, the effect of differential love is dominated by the effect of the household good being a public good. Noting that $\max _{\alpha_{t, i}, \alpha_{t, j}}\left[\frac{1+\max \left(\alpha_{t, i}, \alpha_{t, j}\right)}{2+\alpha_{t, i}+\alpha_{t, j}}\right]=$ $\frac{1+1}{2+1+0}$ we have:

$$
\beta>\frac{2}{3} \Rightarrow\left(2+\alpha_{t, i}+\alpha_{t, j}\right) \beta>1+\max \left(\alpha_{t, i}, \alpha_{t, j}\right)
$$




\subsubsection{Game Structure}

In each period or round of the game, agents independently and simultaneously decide on how much to work in household public good production. Then their levels of love are recalculated and the next round begins. Agents play an infinite number of rounds of this game. It should be noted that this infinite discounted game is equivalent to one with random termination ${ }^{6}$.

Love of agent $i$ towards the partner in period $t$ is captured by $\alpha_{i, t}$. Love is assumed to vary with the amount of work that the partner puts into household public good production: if $j$ works a lot in household public good production, which benefits agent $i$, then $i$ 's love for $j$ increases/stays high. To simplify the notation, I set $\alpha_{i, t}=w_{j, t-1}$ and vice versa for $\alpha_{i, t}{ }^{7}$.

In order to ease the language I shall refer to an agent's love being 'high' when his $\alpha$ is one and shall say he 'works' if his $w$ is one and that he does not otherwise.

\subsubsection{Equilibrium}

The solution concept is Markov-perfect equilibrium so that the state-dependent strategies of the agents must constitute a Nash equilibrium in every state. Statedependency implies that the history of the play of the two players enters their strategy only implicitly through the levels of love of the two agents.

There are then four possible states of love in the relationship of the two agents: writing $\left(\alpha_{i, t}, \alpha_{j, t}\right)$ we can have $(0,0),(1,0),(0,1)$ or $(1,1)$.

We can construct a table of all possible strategies of agent $i$, this is done in Table 1 where for each of the 16 possible strategies I list the value of $w_{i}$ depending on the four states.

\footnotetext{
${ }^{6}$ If agents are mortal and do not know the exact time of their death then their expectation can be modeled as an infinite life with a certain probability of death every period.

${ }^{7}$ In the evolution of love, I am abstracting from factors other the partner's treatment. Other factors would for instance include the presence or absence of children as studied in Grossbard and Mukhopadhyay [2012].
} 
Table 1

\begin{tabular}{|c|c|c|c|c|c|c|c|c|c|c|c|c|c|c|c|c|c|}
\hline \multirow[b]{2}{*}{ state } & \multirow[b]{2}{*}{$\left(\alpha_{i, t}, \alpha_{j, t}\right)$} & \multicolumn{16}{|c|}{ strategies in $w_{i}$ (numbered from 1 to 16 ) } \\
\hline & & 1 & 2 & 3 & 4 & 5 & 6 & 7 & 8 & 9 & 10 & 11 & 12 & 13 & 14 & 15 & 16 \\
\hline$I$ & $(0,0)$ & 0 & 1 & 0 & 0 & 0 & 1 & 1 & 1 & 0 & 0 & 0 & 1 & 1 & 1 & 0 & 1 \\
\hline$I I$ & $(1,0)$ & 0 & 0 & 1 & 0 & 0 & 1 & 0 & 0 & 1 & 1 & 0 & 1 & 1 & 0 & 1 & 1 \\
\hline$I I I$ & $(0,1)$ & 0 & 0 & 0 & 1 & 0 & 0 & 1 & 0 & 1 & 0 & 1 & 1 & 0 & 1 & 1 & 1 \\
\hline$I V$ & $(1,1)$ & 0 & 0 & 0 & 0 & 1 & 0 & 0 & 1 & 0 & 1 & 1 & 0 & 1 & 1 & 1 & 1 \\
\hline ot & S & & & & & & & & & & 1 & & & 1 & & 1 & 1 \\
\hline
\end{tabular}

The last line of Table 1 marks the strategies that are not dominated by some other strategy. The logic behind is the following: in states $I I$ and $I V$, when agent $i$ 's love is high, he is intrinsically motivated to work in the sense that it maximizes his period utility; working also raises the partner's love which is beneficial to $i$ by potentially inducing $j$ to work more than otherwise. Therefore in these states agent $i$ will always choose to work.

The four remaining strategies can be characterized as follows:

- strategy number 10 , renamed to $S$

This is the "selfish strategy". The agent acts as if he was maximizing his current period utility.

- strategy number 13 , renamed to $O$

This is the "optimistic initial investment strategy". When there is no love in the relationship, the agent invests by working.

- strategy number 15 , renamed to $F$

This is the "keep the flame alive strategy". The agent keeps the partner in a loving state.

- strategy number 16 , renamed to $W$

This is the "unconditional work strategy". The agent works under any circumstance.

The same exercise can be conducted for agent $j$ reaching the mirror outcome.

For a pair of strategies to form a Nash equilibrium they must be best responses (BRs) to one another. It will be instructive to calculate the best re- 
sponse function of one agent to any of the four strategies that his partner may follow.

Suppose first that agent $j$ is playing strategy $S$ (defined analogously to how we defined $S$ for agent $i$ ). When computing the best response for $i$ we now need only consider states $O$ and $I I I$ as in the other two states all strategies imply the same course of action and thus lead to the same utility. Consider the possibilities in turn.

- state $I, i$ plays $S$ :

Agents will play $w_{i, t}=w_{j, t}=0$ and therefore perpetuate state $I$. Total expected utility of $i$ is therefore $U_{i, t}=\frac{1}{1-\delta}$.

- state $I, i$ plays $O$ :

Agent $i$ playing $O$ results in a sequence of high and low love alternating; agent $i$, following strategy $O$, starts with working full time since there is no love in the relationship and then in the next period does not as the partner loves him then. The resulting work by partner makes $i$ loving in the following period while the partner will have lost his love. Therefore the cycle alternates between $i$ being in love while $j$ is not and the other way round. This is illustrated in Table 2. Total expected utility of $i$ will thus be $U_{i, t}=\beta+\delta \frac{(\beta+1)+\delta(2 \beta+1)}{1-\delta^{2}}$.

Table 2

\begin{tabular}{cccccc}
\hline & $\alpha_{i, t}$ & $\alpha_{j, t}$ & $w_{i, t}$ & $w_{j, t}$ & $u_{i, t}$ \\
\hline $\mathrm{t}$ & 0 & 0 & 1 & 0 & $\beta$ \\
$\mathrm{t}+1$ & 0 & 1 & 0 & 1 & $\beta+1$ \\
$\mathrm{t}+2$ & 1 & 0 & 1 & 0 & $2 \beta+1$ \\
$\mathrm{t}+3$ & 0 & 1 & 0 & 1 & $\beta+1$ \\
$\mathrm{t}+4$ & 1 & 0 & 1 & 0 & $2 \beta+1$ \\
\hline
\end{tabular}

- state $I, i$ plays $F$ :

This leads to the same situation as when $i$ plays $S$, so we have $U_{i, t}=\frac{1}{1-\delta}$.

- state $I, i$ plays $W$ :

By unconditionally working, agent $i$ raises his partner's love and keeps it high; when his partner has fallen in love as well he switches to working as 
well so that the couple enter a steady state of high love with both working. This is illustrated in Table 3; periods after $t+3$ will have the same stage game action and payoff as $t+3$. The total expected utility of $i$ will then be $U_{i, t}=\beta+\delta 2 \beta+\delta^{2} \frac{4 \beta}{1-\delta}$.

Table 3

\begin{tabular}{cccccc}
\hline & $\alpha_{i, t}$ & $\alpha_{j, t}$ & $w_{i, t}$ & $w_{j, t}$ & $u_{i, t}$ \\
\hline $\mathrm{t}$ & 0 & 0 & 1 & 0 & $\beta$ \\
$\mathrm{t}+1$ & 0 & 1 & 1 & 1 & $2 \beta$ \\
$\mathrm{t}+2$ & 1 & 1 & 1 & 1 & $4 \beta$ \\
\hline
\end{tabular}

- state $I I I, i$ plays $S$ :

Here, the agents also enter a sequence of alternating love and work; total expected utility of $i$ will be $U_{i, t}=\frac{(\beta+1)+\delta(2 \beta+1)}{1-\delta^{2}}$. See Table 4 .

Table 4

\begin{tabular}{cccccc}
\hline & $\alpha_{i, t}$ & $\alpha_{j, t}$ & $w_{i, t}$ & $w_{j, t}$ & $u_{i, t}$ \\
\hline $\mathrm{t}$ & 0 & 1 & 0 & 1 & $\beta+1$ \\
$\mathrm{t}+1$ & 1 & 0 & 1 & 0 & $2 \beta+1$ \\
$\mathrm{t}+2$ & 0 & 1 & 0 & 1 & $\beta+1$ \\
$\mathrm{t}+3$ & 1 & 0 & 1 & 0 & $2 \beta+1$ \\
\hline
\end{tabular}

- state $I I I, i$ plays $O$ :

The result is the same as if $i$ played $S$.

- state $I I I, i$ plays $F$ :

In this case, agent $i$ keeps his partner's love high and thus the couple enters the high love steady state with both working. Total expected utility is $U_{i, t}=2 \beta+\delta \frac{4 \beta}{1-\delta}$; see Table 5 .

Table 5

\begin{tabular}{cccccc}
\hline & $\alpha_{i, t}$ & $\alpha_{j, t}$ & $w_{i, t}$ & $w_{j, t}$ & $u_{i, t}$ \\
\hline $\mathrm{t}$ & 0 & 1 & 1 & 1 & $2 \beta$ \\
$\mathrm{t}+1$ & 1 & 1 & 1 & 1 & $4 \beta$ \\
$\mathrm{t}+2$ & 1 & 1 & 1 & 1 & $4 \beta$ \\
\hline
\end{tabular}


- state $I I I, i$ plays $W$ :

The result is the same as if $i$ played $F$.

For state $I$ we can construct the following rankings of total expected utility:

$$
\begin{aligned}
&\{S, F\} \succ O \Leftrightarrow \frac{1}{1-\delta}>\beta+\delta \frac{(\beta+1)+\delta(2 \beta+1)}{1-\delta^{2}} \quad \Leftrightarrow \quad \delta<\hat{\delta}_{A 1} \\
& O \succ W \Leftrightarrow \quad \beta+\delta \frac{(\beta+1)+\delta(2 \beta+1)}{1-\delta^{2}}>\beta+2 \delta \beta+\delta^{2} \frac{4 \beta}{1-\delta} \Leftrightarrow \quad \delta<\hat{\delta}_{A 2}
\end{aligned}
$$

It can be shown that $\hat{\delta}_{A 1}=-\frac{\beta}{2(1+\beta)}+\sqrt{\left(\frac{\beta}{2(1+\beta)}\right)^{2}+\frac{1-\beta}{1+\beta}}<=-\frac{2 \beta-1}{4 \beta}+\sqrt{\left(\frac{2 \beta-1}{4 \beta}\right)^{2}-\frac{1}{2}+\frac{1}{2 \beta}}=$ $\hat{\delta}_{A 2}$.

And for state $I I I$ we have the following ranking:

$$
\{S, O\} \succ\{F, W\} \Leftrightarrow \frac{(\beta+1)+\delta(2 \beta+1)}{1-\delta^{2}}>2 \beta+\delta \frac{4 \beta}{1-\delta} \Leftrightarrow \delta<\hat{\delta}_{A 3} .
$$

\begin{tabular}{|c|c|c|c|c|c|c|}
\hline & 0 & & $\hat{\delta}_{A 1}$ & & $\hat{\delta}_{A 2}$ & \\
\hline state $I$ & | & $\mathrm{S} / \mathrm{F}$ & $\mid$ & $\mathrm{O}$ & $\mid$ & W \\
\hline state $I I I$ & | & $\mathrm{S} / \mathrm{O}$ & | & $\mathrm{S} / \mathrm{O}$ & | & $\mathrm{F} / \mathrm{W}$ \\
\hline both states & 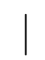 & $\mathrm{S}$ & | & $\mathrm{O}$ & & W \\
\hline
\end{tabular}

It is easy to see that $\hat{\delta}_{A 3}=\hat{\delta}_{A 2}$.

We arrive at the following best response function of $i$ to $j$ playing $S$ :

In the above manner we can likewise derive the best response functions of $i$ to $j$ playing some other strategy; the results are listed below. For a derivation see the Appendix. 


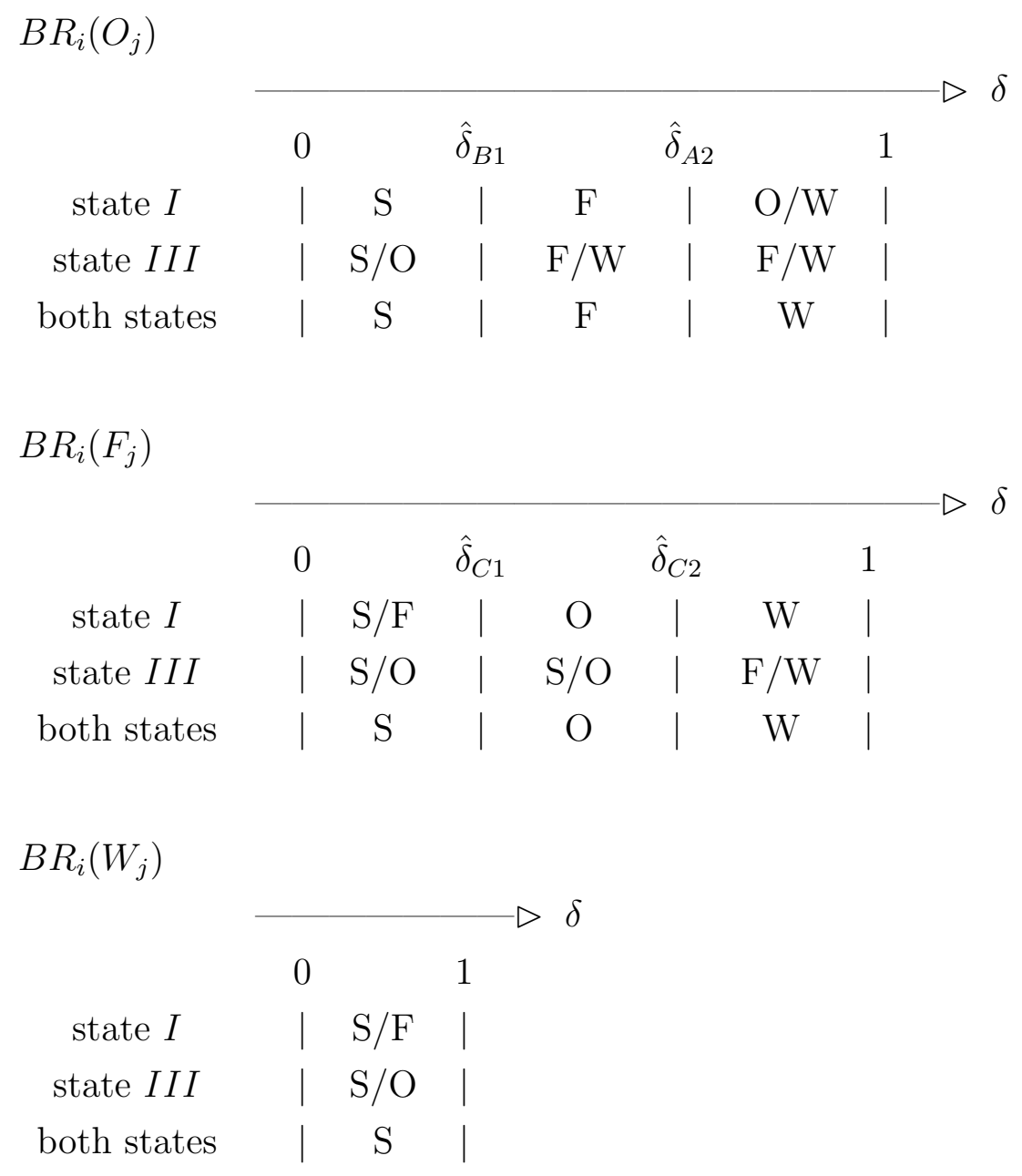

We can now take these best responses together and work out which equilibria may emerge in this game. The result is plotted in Figure 1.1.

\section{Proposition 1 Characterization Theorem}

We have the following equilibria depending on which area in the allowable $(\beta, \delta)$ space the game is set in (for the numbering of areas refer to the right part of Figure 1.1). The equilibrium strategy pairs are depicted in $(\beta, \delta)$ space in Figure 1.2. 

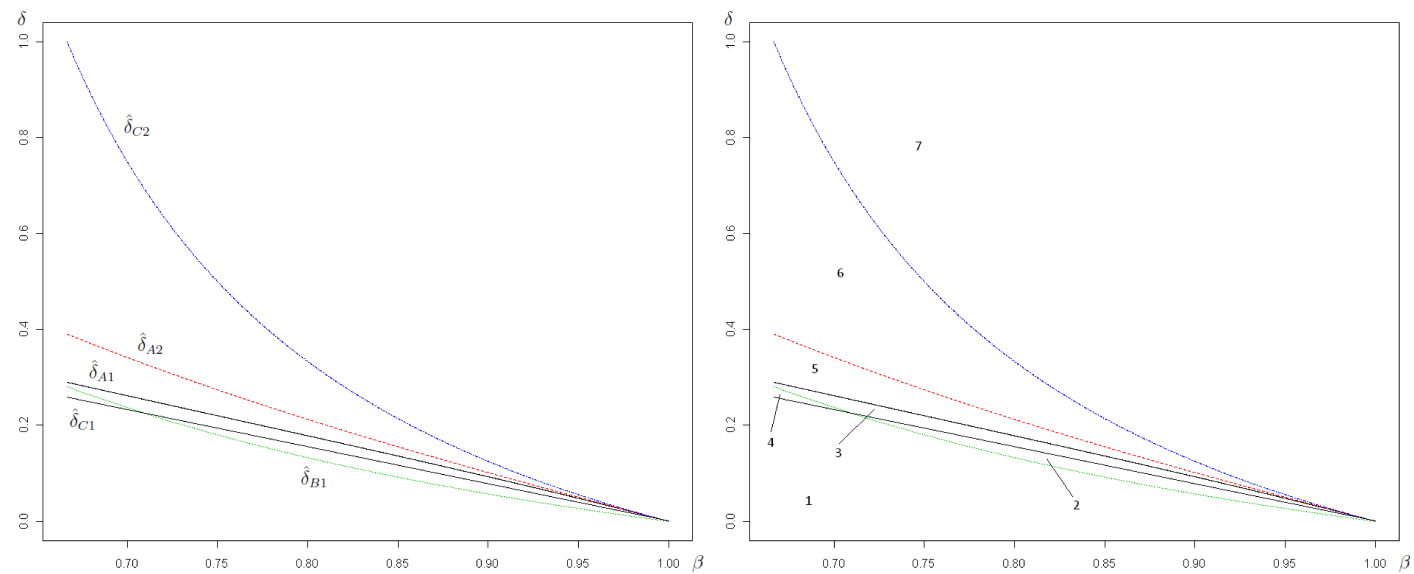

Figure 1.1: The graph on the left shows the locations of the $\hat{\delta} s$ in $(\beta, \delta)$ space. The graph on the right shows the numbering of the resulting areas.

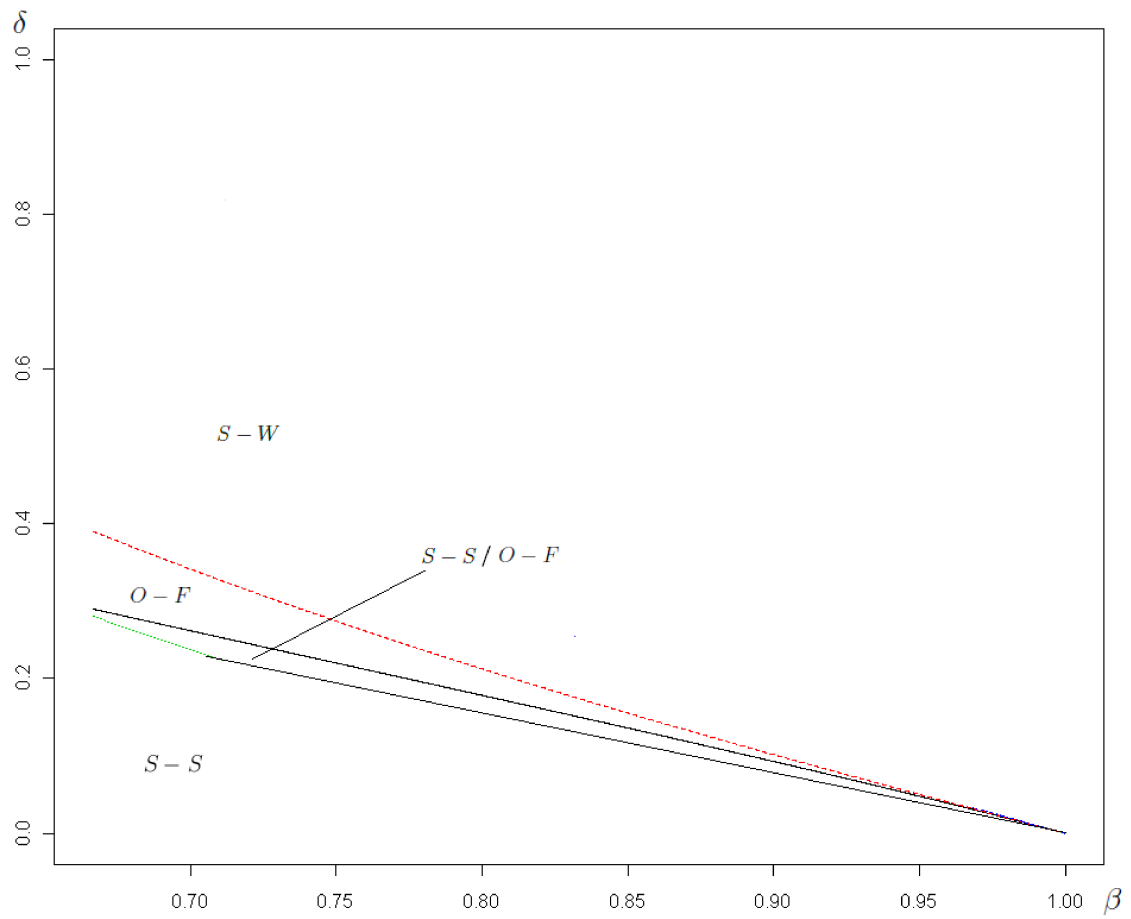

Figure 1.2: The graph shows the existence of equilibria according to Proposition 1 . 


\begin{tabular}{lccccccc}
\hline area & 1 & 2 & 3 & 4 & 5 & 6 & 7 \\
\hline$B R_{i}(S)$ & $S$ & $S$ & $S$ & $S$ & $O$ & $W$ & $W$ \\
$B R_{i}(O)$ & $S$ & $F$ & $S$ & $F$ & $F$ & $W$ & $W$ \\
$B R_{i}(F)$ & $S$ & $S$ & $O$ & $O$ & $O$ & $O$ & $W$ \\
$B R_{i}(W)$ & $S$ & $S$ & $S$ & $S$ & $S$ & $S$ & $S$ \\
\hline \multirow{2}{*}{ equilibria } & \multirow{2}{*}{$S-S$} & \multirow{2}{*}{$S-S$} & $S-S$ & $S-S$ & & \\
& & & & & $O-F$ & & \\
\end{tabular}

Proof: Follows immediately from the best responses.

The intuition for this result is that when agents are impatient, they do not invest into the relationship and rather resort to the 'selfish strategy' that yields the highest immediate satisfaction. This means that agents who initially feel no love towards each other remain trapped in that state. If one agent feels love and the other does not then they enter a sequence of alternating love. In the latter case neither is willing to sacrifice current period utility in order to lift the couple to the full love steady state.

Unless the agents happen to start in the full love state, they will never get there.

When agents are more patient, they may co-ordinate on the selfish strategy equilibrium but may also co-ordinate on the $O-F$ equilibrium. In the latter, the partners can escape the state of no love by sharing the burden of investment: in the first period one makes the initial investment while the other invests into his partner's love two periods later, saving the agents from entering an alternating sequence of love and no love.

The 'optimistic initial investment strategy' and the 'keep the flame alive strategy' are thus complementary in their effort to move agents from the no love to the full love state. This equilibrium is the closest that the agents may get to a symmetric investment equilibrium.

Yet more patient agents will always play the shared-burden equilibrium of $O-F$. If one of the agents played the selfish strategy $(S)$, then the other would want move in to make the initial investment thereby destroying the selfish strategy equilibrium.

When agents are very patient then one will choose the 'unconditional work strategy' meaning he will work whatever the levels of love and so propel the 
couple to the state of full love. The other agent's best response will be to, figuratively speaking, lay back and let the partner do the work, i.e. the selfish strategy. The underlying reason for this best response is that the speed with which agents reach the full love state cannot be increased by the agent whose partner is playing the unconditional work strategy and therefore there can be no incentive for the agent to invest. It is for this reason that even very patient agents cannot play a symmetric investment equilibrium.

The burden sharing equilibrium is destroyed when agents are very patient: the best response to the optimistic initial investment strategy $(O)$ is no longer the keep the flame alive strategy $(F)$ but the unconditional work strategy. This is so because the partner that would have played $F$ before now is patient enough to invest early on.

It is worth noting that $\beta$ is a substitute for $\delta$ in that the threshold levels of patience that separate the discussed areas from each other are strictly decreasing functions of the productivity of agents in household public good production. In fact even the most impatient pair of agents may play the strategy pair $S-W$, i.e. reaching the full love steady state from an initial state of no love, if $\beta$ is close enough to unity.

The intuition to this result is simple: the higher the productivity in household public good production, the lower the negative utility differential between work and leisure for a non-loving agent and hence the lower the cost of investing into the love of the partner.

\subsection{Outlook: Potential for Testing}

It is possible to derive testable hypotheses from the model and link these to existing data sources.

As to the data, one can refer to a household survey panel such as the British Household Panel Survey (BHPS) or the National Longitudinal Survey of Youth 1997 (NLSY). From their questions an approximation of the savings rate of a household can be derived which, potentially mediated by some control variables, one can take to be a proxy for the patience of the couple $(\delta)^{8}$. It is also possible

\footnotetext{
${ }^{8}$ See Leece [2004] and van de Ven [2009] for similar interpretations of the BHPS data.
} 
to extract the approximate amount of time not dedicated to paid work which one can take to be a proxy for the productivity of household public goods production $(\beta)$ - as more time outside work should by virtue of diminishing marginal utility of non-spouse related activities ceteris paribus lower the opportunity costs of spending time on things that please the partner.

In recent waves of BHPS, Self Completion Questionnaire question 3 part d) asks the interviewee to rate how satisfied he or she is with 'Your husband/wife/partner' on a scale from 1 to 10. Similarly, the NLSY asks the interviewee "How do you feel that [your current spouse/partner] cares about you?". While these questions are not exactly aimed at the level of love or affection towards the partner, one can take them to be at least correlated to love $(\alpha)^{9}$. In order to control for preference heterogeneity not accounted for in the model, in the BHPS data one could bin observations by the responses to Individual Questionnaire question RV94 which asks the interviewee to rate the importance of 'Having a good marriage or partnership' on a scale from 1 to 10.

Hypotheses could include the following: a higher savings rate is associated ceteris paribus with a higher score on the question serving as a proxy for love as more patient partners have been shown to arrive in a high love equilibrium given a wider range of values of $\beta$ than less patient couples. Exogenous variance of leisure hours, e.g. by instrumenting out with regional cyclical ups and downs or with average of the profession, on the other hand should give an indication of exogenous variation in $\beta$ where again high values should ceteris paribus correspond to higher levels of love for reasons analogous to before.

Applied for instance to an empirical framework such as Grossbard and Mukhopadhyay [2012], one would expect to find that these proxies for $\delta$ and $\beta$ explain part of the unobserved heterogeneity across people that is controlled for by a fixed effects setting.

If one were to interpret BHPS question RV94 not as being informative about preferences but rather as being a description or rationalisation of compromise in household decision-making, then its score would be an indication of time spent in household public good production $(w)$. One could then compute the difference in difference of love and time spent in household public good production

\footnotetext{
${ }^{9}$ For related empirical papers working on this question in the BHPS data see Powdthavee [2009] and Anand et al. [2005].
} 
which according to the assumptions of the model should indicate that the latter increases the former.

\subsection{Conclusions}

The purpose of the model presented here was to illustrate the dynamics that two people enter when they form a couple. If their mutual feelings are endogenous to their relationship then the treatments of the respective partner, which is exemplified in the choice of how much time one invests in household public good production, are a strategic interaction: the better I treat him/her the more he/she will love me, which alters his/her incentives in the future. The parameters were chosen such that loving agents would intrinsically want to treat their partner nicely while unloving agents would prefer not to treat their partner nicely.

Not surprisingly, in equilibrium agents are able to lift themselves out of the no-love state into a loving state if the costs of doing so are low enough and if they are patient enough. From an incentive point of view, agents may be said to realize that their partner's and their own love is an investment good which pays dividends by altering the agents preferences so that their utility is higher in the loving state.

Interestingly, agents do not only invest into their partner's love so that the partner treats them nicely - which could be interpreted as love being a currency that facilitates the non-simultaneous exchange of goods - but also in order to have their own love grow in response to this nice treatment. In a strongly simplified form, the model thus illustrates the arduous process of building deep mutual feelings of affection, caring, trust, dependability - or, in one, love. It also illustrates the complementarity of investments specific to one person which makes such love hard to build and thus worth preserving.

From an application point of view, it is worth noting that for less patient agents who face greater risk of divorce or breakup the initial level of love play a greater role in the long run well-being of the partner. Hence, perhaps, the greater emphasis on these in recent times ${ }^{10}$.

\footnotetext{
${ }^{10}$ This refers only to a relative shift in importance, not to any ranking in terms of well-being.
} 
If human preferences are indeed structured in such or similar fashion, love could be interpreted as the facilitator that allows two people to form a productive partnership. And this for two reasons: firstly, in a setting with little institutional background, it provides a commitment device that makes opportunistic behavior costly in a relationship; secondly, investment into love creates a positive feedback into the productivity of such investment by raising one's own love, and this strategic complementarity focuses efforts on a single individual partner further strengthening the couple as a productive unit. ${ }^{11}$

Promising avenues for future research include widening the scope of the model to more explicitly include aspects like risk and long term decisions. In the former domain one could study the effect of the possibility of divorce or unemployment; in the latter domain joint ownership of the home and having children could be investigated.

Both these domains would take the model closer to the central issues in empirical household economics and would thus sharpen the empirical implications of the presented model. For now, these implications are that exogenous variation in patience as well as in ease and leisure to please the partner of one or both partners of a relationship will partly explain levels of affection and love of both partners.

For the latter, see e.g. Xiaohe and Whyte [1990] for an empirical investigation.

${ }^{11}$ This latter point is perhaps what separates the analysis of love from the one of friendship and affection. 


\section{Chapter 2}

\section{Perception of Technology and Technological Progress under Extractive Institutions}

\section{$2.1 \quad$ Introduction}

Malthus has been proven rather conclusively wrong by the last two centuries: productivity growth has clearly been exponential as opposed to linear as posited by him in $1798^{1}$; and it is now widely believed it had been such in the preceding centuries as well. Yet the furore his book made is a clear testament to the fact that the answer to the question of the nature of technological growth was far from clear in his time ${ }^{2}$.

This paper is about the implications of uncertainty over the nature of technological growth. It sets out to show that depending on the belief that the decision-makers, or elite, hold concerning its nature, societies will embark on very different growth paths. These beliefs are shown to be self-fulfilling in a sense: there is more investment if growth is believed to be exponential, or 'geometric', and there is less if it is believed to be linear, or 'arithmetic'.

\footnotetext{
${ }^{1}$ See Malthus [1798].

${ }^{2}$ Even today there is considerable debate on the true nature of technological growth. For recent contributions critical of the naive geometric interpretation see for instance Cowen [2011] or Gordon [2012]. Then compare to for instance Brynjolfsson and McAfee [2011]
} 
Yet the more interesting insight is historical: in the course of time not only the number of observations on the rewards of investment into technology increases but also the information content of each. This is because the advancing level of technology makes it ever easier to distinguish between these two hypotheses on the nature of technology. The result is that, with technology in truth following a geometric pattern, over time more and more societies will switch their beliefs in favour of the geometric hypothesis and consequently start investing (more) into technology. As long as there is some technological advancement therefore, the true nature will ultimately reveal itself and global investment into innovation and global growth will in the end take off. Growth thus begets growth.

Behind the very proximate causes of growth, it can be argued, there are then at least three layers of subsequent causes: first the incentive structure or the institutional setup of a society, then the perception of technology by those who can change the rules of the game, and finally the true nature of technology itself. It is pointing to the existence of this middle layer that is the contribution of this paper.

The next section reviews the related literature followed by the exposition of a simple model of extractive institutions that nests two regimes of technological growth: exponential and arithmetic. We study the resulting decisions on investment into innovation and in an extension also study the incentives of the elite to adopt some inclusive institutions. The ensuing extension nests the two regimes in a model that assumes that there is uncertainty over the nature of technological growth. The final section concludes.

\subsection{Related Literature}

Recent years have seen a surge of papers on the importance of institutions for economic growth. Following North and Thomas [1970, 1973] and North [1981, 1990], institutions are usually defined as commonly known rules used to structure recurrent interaction situations that are endowed with a sanctioning mechanism - in short 'the rules of the game' of a society. When the focus is on their socially beneficial effect, institutions are sometimes referred to as 'social infrastructure' that aligns private and social returns to activities; compare Hall and Jones 
[1999].

Authors such as Rodrik et al. [2004] and Acemoglu et al. [2005] argue that an empirical causal link can be established between institutional quality and economic performance of countries. The economic rationale of the causal link is that institutions create or fail to create the incentives that motivate people to invest in growth enhancing human and real capital as well as the incentives to engage in innovative and entrepreneurial behaviour; this reasoning is put into models in e.g. Acemoglu [2006] and Robinson [2006]. The hypothesis is that the ultimate cause for growth lies in the institutional setup of societies while commonly identified factors such as "innovation, economies of scale, education capital accumulation [...] are not causes of growth; they are growth" (North and Thomas [1970]).

The tenet of this literature is that the institutional setup not only influences the speed of technological advancement but also determines whether or not it can take place at all in the modern, disruptive fashion that the Western world has experienced since the beginning of the Industrial Revolution. As introduced in Acemoglu et al. [2001] and popularised in Acemoglu and Robinson [2012], 'extractive institutions' - that are tailored to the enrichment of a relatively small elite - are considered not compatible with modern growth.

If institutions are such a decisive factor of growth and this is commonly known, then the ensuing question, and the question that this paper contributes a new answer to, is why such apparently inefficient institutions survive for long periods of time. The literature has proposed a diverse range of answers so far ${ }^{3}$ :

1. In some guise or other, a large part of the literature argues that institutions are born out of social conflict in which groups and coalitions try to impose institutional structures on society that further their own interest. Such conflict is discussed for example in Gradstein [2008] and Barseghyan and Guerdjikova [2011]. In a similar vein, dictators may prefer low average income infrastructures because the larger pie of higher incomes may come with disproportionately higher risk of political turnover; compare for instance De Long and Shleifer [1993]. Lastly, it may be difficult to devise a system of transition towards more efficient institutions that credibly

\footnotetext{
${ }^{3}$ The categorisation builds on Asoni [2008] and Romer [2006].
} 
promises a 'parasitic' elite remuneration or compensation in the process; see for instance Mokyr [1990], Shleifer and Vishny [1993], Parente and Prescott [1999], Jones [2003] and Acemoglu and Robinson [2000, 2006].

2. Papers such as Knack and Keefer [1997] and La Porta et al. [1997] argue that institutions reflect deeper cultural settings and in particular levels of trust towards strangers. Easterly and Levine [1997] in turn posit that ethnic diversity could be the ultimate cause of such culture.

Recent empirical investigations such as Guiso et al. [2008] and Algan and Cahuc [2010] indeed point to a large role for generalised trust both in cross-country comparisons and in the success of coherent subgroups of society over time. As is evident from papers such as Fehr [2009], however, the question whether trust is rather an independently determined factor in economic development or a byproduct of good institutions is far from settled.

3. Part of the literature argues that the question is framed wrongly in that societies choose efficient institutions and apparent inefficiencies neglect constraints on the solution. Cervellati et al. [2008] for instance argue that oligarchies emerge when the inequality in a society is high so that the disenfranchised groups tolerate the rule of the few because it is not worth to engage in costly open contest for political power - these oligarchies are thus efficient in a politically constrained sense.

Politically constrained institutional setups have also been studied extensively over time. As examples, Huang [2012] aims to model the transitions from one political system to another as solutions to changes in the relative importance of factors of production while Sekeris [2011] decomposes the (parasitic) elite and highlights the effects on development depending on its endogenous composition.

4. A less extreme form of this approach is to say that societies choose ex ante efficient institutional setups and that inefficient institutions are the result of their inertia as circumstances change or new information becomes available. As an example Sachs and Warner [1995] emphasise that after World War II it was not so clear whether the USA or the UdSSR had the better system. Krueger [1993] provides an example of a 'vicious circle', i.e. benevolent leaders or the majority choose the wrong path and this 
path then entrenches the wrong social infrastructure. Such entrenchment is for instance modelled in Acemoglu et al. [2003, 2006, 2010] who argue that economies that are far behind the world technological frontier can achieve faster growth by favouring investment over innovation while for technologically advanced economies a bias towards innovation is appropriate; the danger being that a policy of favouring investment may lead to entrenched interests and thus be self-perpetuating beyond the point of being appropriate.

This paper can be associated with group number 3: We take the existence of a parasitic elite as given and not challenged inside the model so that the decisions of the elite are motivated only by economic, not political, concerns. The equilibria of our model are thus efficient in a politically constrained sense as in Cervellati et al. [2008]. The elite views institutions as a technology by which to produce income for itself and it is, in our model, largely down to the perception of technology and technological possibilities whether the elite seeks to increase its share of the pie or to enlarge the pie. For our paper politically constrained efficiency is, however, only an assumption and a static feature of the model, not the area of interest.

It can also be associated with group number 4: In the last extension, we introduce uncertainty over the nature of technological growth. Societies choose institutional setups, in the sense of tax rates, based on their beliefs concerning this nature; wrongly believing in arithmetic growth (the limited growth case) then translates into getting trapped in a low investment and thus low growth equilibrium. We thus provide a different fundamental on top of which path dependent institutional development can take place as in for instance Sachs and Warner [1995] and Acemoglu et al. [2010].The key difference to group number 4 is that there is neither uncertainty over the efficiency of different institutional setups nor do institutions get entrenched. Path dependency is based rather on differences in the nature of technology and uncertainty thereof.

In the sense that growth opportunities are weighed against the share of the output that can be appropriated by the elite, one may also draw parallels to group number 1 of the literature discussed above, in particular Gradstein [2008]. We do not, however, contemplate political conflict in our model which we believe 
to be the defining feature of that branch.

Our argument is built in the setting of a so-called linear growth model. In particular, we take a simplified discrete time version of the models employed in Romer [1990] and Aghion and Howitt [1992] and extend it to nest two different technological growth regimes as well as to accommodate the presence of a parasitic elite.

In a vein similar to Kremer [1993] and Galor and Weil [1993, 1999], yet from a different perspective, we are going to argue that slow growth eventually triggers fast growth - the difference being that the decisive variable is not the level of the population nor the return to human capital but the perception of the nature of technology held by the society.

\section{$2.3 \quad$ Model Setup}

Imagine a society composed for simplicity of exactly one serf and one aristocrat, the former being subject to the latter. The two agents live forever; the serf works and produces output while the aristocrat only taxes the serf and consumes. The system is stable in that there are no rebellions or revolutions.

Imagine further that the economy of this society has the labour of the serf as its only input factor. Output therefore depends on the labour productivity of the serf alone, which depends on the investments into innovation in previous periods by the serf. Specifically, let productivity of the serf in period $t$ be given by $A_{t}$.

In the notational convention of linear growth models set in discrete time, the net output of the economy can thus be written in the following form:

$$
Y_{t}=\left(1-a_{L}\right) L_{t} A_{t}
$$

Labour $L_{t}$ is assumed constant and normalised to 1 (the labour of the serf). The investment decision by the serf into innovation is represented by $a_{L}$ which for simplicity is restricted to be a binary decision in that $a_{L} \in\{0, c\}$ with $c \in(0,1)$. For expositional purposes, we shall now introduce the indicator variable $I_{t}$ which is equal to 1 if the serf innovates in period $t$ and 0 otherwise. The dynamics of 
technology in response to investment are as follows:

$$
A_{t}=A_{t-1}+g I_{t-1}\left[(1-\theta)+\theta A_{t-1}\right]
$$

The behaviour encoded in this equation is nonstandard as it adds the twist of different growth regimes which are represented by $\theta \in[0,1]$. At the extremes, $\theta=0$ makes investment return a constant $g$ providing a scenario of linear or 'arithmetic' growth while for $\theta=1$ investment return is a constant fraction $g$ of productivity thus giving rise to exponential or 'geometric' growth. Unless stated otherwise, we assume that the initial level of technology is equal to one, $A_{0}=1$, so that the initial payoff to investing is independent of the value of $\theta$.

Utility is assumed to be linear in consumption. The serf is coerced to work one unit of time every period but is free to decide whether to invest in innovation or not. Output of the serf in period $t$ is thus simply $A_{t}$, his only decision variable is $I_{t}$ and his utility function is given by:

$$
U_{t}^{\text {serf }}=\sum_{\tau=t}^{\infty} \delta^{\tau-t}\left[\left(1-T_{\tau}\right) A_{\tau}-c I_{\tau} A_{\tau}\right]
$$

Where $c$ is the above introduced constant cost parameter associated with innovative behaviour. Note that the cost of innovation is assumed to scale proportionally with the level of technology ${ }^{4} . c$ is taken as exogenous because we see the investment into new technology as a holistic enterprise that is not scalable by the agents at will. $\delta \in(0,1)$ is the time discount parameter common to serf and aristocrat. In order to rule out some pathological cases we restrict $\delta(1+g) \theta<1$. $T_{\tau}$ is the tax rate in period $\tau$ expressed in percentage of gross output in period $\tau^{5}$.

The aristocrat only decides on the level of the tax and his utility function is then simply given by:

$$
U_{t}^{\text {aris }}=\sum_{\tau=t}^{\infty} \delta^{\tau-t} T_{\tau} A_{\tau}
$$

\footnotetext{
${ }^{4}$ This can be motivated by diminishing returns in the search for new technologies. Actual research and development spending in the United States is indeed roughly a constant fraction of GDP.

${ }^{5}$ One could also model taxes as a percentage of net production, i.e. after having deducted innovation costs, we are following the literature in this formulation. See for instance Acemoglu [2006].
} 
The main tension in this model stems from the facts that an increase in total production is only possible by investment on behalf of the serf and that the fruits of this investment are insecure from his viewpoint as they can be appropriated in their entirety by the aristocrat. From the point of view of the aristocrat the challenge is to take as much away from the serf as possible and still induce him to innovate.

Before moving to the equilibrium analysis, it is instructive to consider first the socially efficient outcome which is given by the maximised discounted sum of net production - which happens in our case to be equal to the serf's utility in the absence of taxes because utility is linear in consumption.

Solving for the socially efficient outcome is simplified by the fact that it is not socially efficient to postpone investment into innovation:

\section{Lemma 1 Socially inEFFICIENT TO POSTPONE INNOVATION}

Let the sequence of investment decisions in an efficient outcome starting in period $t$ be written as $I^{P}$ with the investment decision in period $\tau \geq t$ thus being $I_{\tau}^{P}$. We then have that if $I_{\tau}^{P}=0$ then also $I_{\tau+1}^{P}=0$.

Proof: We show this result by contradiction. Let $I^{P}$ be a putative efficient outcome with $I_{\tau}^{P}=0$ and $I_{\tau+1}^{P}=1$ for some $\tau$. This putative efficient outcome being socially optimal requires output associated with the path given by $I^{P}$ to be greater or equal to the output of any alternative paths. Specifically, $U_{t}^{\text {serf }}\left(I^{P} \mid T_{n}=0 \forall n\right) \geq \max _{x}\left[U_{t}^{\text {serf }}\left(I^{A x} \mid T_{n}=0 \forall n\right)\right]$ where we have:

$$
\begin{aligned}
& I^{A 1}=\left\{I_{t \leq n<\tau}^{P}, 1,1, I_{n \geq \tau+2}^{P}\right\} \\
& I^{A 2}=\left\{I_{t \leq n<\tau}^{P}, 0,0, I_{n \geq \tau+2}^{P}\right\} \\
& I^{A 3}=\left\{I_{t \leq n<\tau}^{P}, 1,0, I_{n \geq \tau+2}^{P}\right\}
\end{aligned}
$$

The output, or serf utility in the absence of taxes as noted above, can be written 
as:

$$
\begin{gathered}
U_{t}\left(I^{P} \mid T_{n}=0 \forall n\right)=\sum_{n=t}^{\tau-1} \delta^{n-t} A_{n}\left(1-c I_{n}^{P}\right)+\delta^{\tau-t} A_{\tau}+\delta^{\tau+1-t} A_{\tau}(1-c)+ \\
\delta^{\tau+2-t} U_{\tau+3}\left(I_{n \geq \tau+2}^{P} \mid T_{n}=0 \forall n\right) \\
U_{t}\left(I^{A 1} \mid T_{n}=0 \forall n\right)=\sum_{n=t}^{\tau-1} \delta^{n-t} A_{n}\left(1-c I_{n}^{P}\right)+\delta^{\tau-t} A_{\tau}(1-c)+ \\
\delta^{\tau+1-t}\left((1+\theta g) A_{\tau}+(1-\theta) g\right)(1-c)+ \\
\delta^{\tau+2-t}\left[\frac{(1+\theta g)^{2} A_{\tau}+(1+\theta g)(1-\theta) g+(1-\theta) g}{(1+\theta g) A_{\tau}+(1-\theta) g} A+B\right] \\
U_{t}\left(I^{A 2} \mid T_{n}=0 \forall n\right)=\sum_{n=t}^{\tau-1} \delta^{n-t} A_{n}\left(1-c I_{n}^{P}\right)+\delta^{\tau-t} A_{\tau}+\delta^{\tau+1-t} A_{\tau}+ \\
\delta^{\tau+2-t}\left[\frac{A_{\tau}}{(1+\theta g) A_{\tau}+(1-\theta) g} A+B\right] \\
U_{t}\left(I^{A 3} \mid T_{n}=0 \forall n\right)=\sum_{n=t}^{\tau-1} \delta^{n-t} A_{n}\left(1-c I_{n}^{P}\right)+\delta^{\tau-t} A_{\tau}(1-c)+ \\
\delta^{\tau+1-t}\left((1+\theta g) A_{\tau}+(1-\theta) g\right)+ \\
\delta^{\tau+2-t} U_{\tau+3}\left(I_{n \geq \tau+2}^{P} \mid T_{n}=0 \forall n\right)
\end{gathered}
$$

Where we make use of the fact that given future investment choices future output is a linear function of the start level of technology; the constants are labelled by $A$ and $B$, they are positive and functions of $I^{P}$. We thus have $U_{\tau+3}\left(I_{n \geq \tau+2}^{P} \mid T_{n}=0 \forall n\right)=A+B$. If $I^{P}$ was the socially optimal, then the following three conditions have to hold:

$$
\begin{gathered}
U_{t}\left(I^{P} \mid T_{n}=0 \forall n\right) \geq U_{t}\left(I^{A 1} \mid T_{n}=0 \forall n\right) \Longleftrightarrow \\
\delta^{2}(A+B) \geq-c A_{\tau}+\delta\left[\theta g A_{\tau}+(1-\theta) g\right]+ \\
\delta^{2}\left[\frac{(1+\theta g)^{2} A_{\tau}+(1+\theta g)(1-\theta) g+(1-\theta) g}{(1+\theta g) A_{\tau}+(1-\theta) g} A+B\right] \\
U_{t}\left(I^{P} \mid T_{n}=0 \forall n\right) \geq U_{t}\left(I^{A 2} \mid T_{n}=0 \forall n\right) \Longleftrightarrow \\
\delta^{2}(A+B) \geq \delta c A_{\tau}+\delta^{2}\left[\frac{A_{\tau}}{(1+\theta g) A_{\tau}+(1-\theta) g} A+B\right] \\
U_{t}\left(I^{P} \mid T_{n}=0 \forall n\right) \geq U_{t}\left(I^{A 3} \mid T_{n}=0 \forall n\right) \Longleftrightarrow \\
(1-\delta) c A_{\tau}-\delta\left[\theta g A_{\tau}+(1-\theta) g\right] \geq 0
\end{gathered}
$$


We are now going to show that these three conditions cannot hold simultaneously. Insert inequality (2.12) into inequality (2.14) and rearranging yields:

$\delta A_{\tau} c \geq(1+\delta)\left(\theta g A_{\tau}+(1-\theta) g\right)+\delta^{2} A\left[\frac{(1+\theta g)^{2} A_{\tau}+(1+\theta g)(1-\theta) g+(1-\theta) g}{(1+\theta g) A_{\tau}+(1-\theta) g}-1\right] \equiv \hat{c}_{1}$

Rearranging inequality (2.13) gives us a second condition on $c$ :

$$
\delta A_{\tau} c \leq \delta^{2} A\left[1-\frac{A_{\tau}}{(1+\theta g) A_{\tau}+(1-\theta) g}\right] \equiv \hat{c}_{2}
$$

Inequalities (2.15) and (2.16) are easily shown not to be satisfied simultaneously as $\hat{c}_{1}>\hat{c}_{2}$.

The intuition behind this result is possibly made more accessible by the following sequence of logic: imagine that the agents are very patient so that $\delta \rightarrow 1$, then postponing an investment makes no sense as the discounted utility cost stays the same while the discounted utility gain is lower. So the agents would have to be impatient in order to let $I^{P}$ beat $I^{A 3}$.

They cannot be be all too impatient though, because very impatient agents would prefer simply not to invest. There is thus a lower bound on $\delta$ to allow $I^{P}$ to beat $I^{A 2}$. This lower bound will obviously relate to $A$, meaning the influenceable part of the stream of output after $\tau+1$, because that captures the return of investment.

The putative optimality of $I^{P}$ then breaks down in the comparison with the last alternative, $I^{A 1}$. In order to support the lower bound on $\delta$ needed for $I^{P}$ to beat $I^{A 2}$ we would need $A$ to be high, so high as to make the invest in both periods alternative $I^{A 1}$ beat $I^{P}$. It is a sort of vicious circle that makes it impossible for $I^{P}$ to be simultaneously more efficient than all alternatives.

We have thus shown that investment is never postponed in the socially optimal outcome which leaves just three candidate scenarios for the social optimum:

\section{Proposition 2 The socially efficient Path of InVESTMEnT}

The socially optimal path of technology is characterised by one of the following path of investment into innovation:

1. $I_{\tau}=0 \forall \tau \geq t$, 'never invest', iff $A_{0} \geq \frac{g \delta(1-\theta)}{c(1-\delta)-g \delta \theta} \equiv \hat{A}$ 

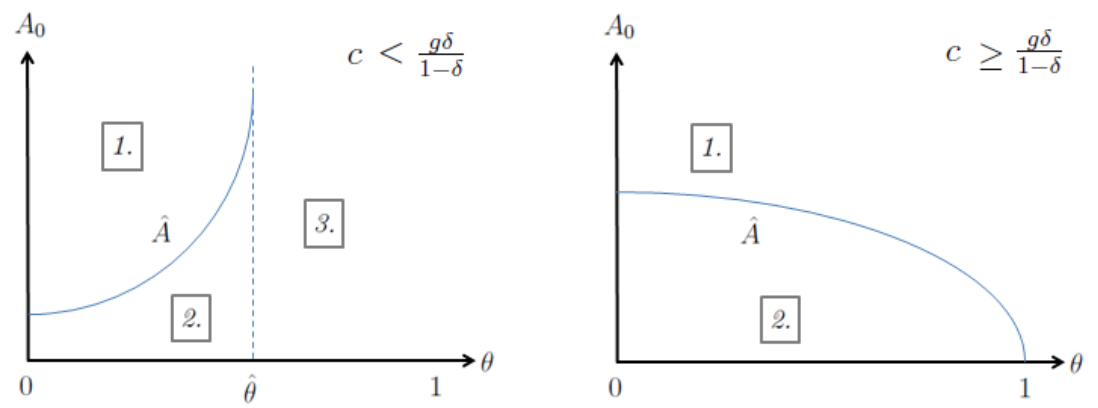

Figure 2.1: This diagram shows the regions defined in Proposition 1 in the parameter space of $\theta$ and $A_{0}$. The regions are mutually exclusive and exhaustive; they are labelled as in the Proposition and marked by grey boxes. Note that the behaviour of $\hat{A}$ changes depending on whether $c$ is greater or smaller $\frac{g \delta}{1-\delta}$ and thus on whether the 'always invest' case exists or not.

2. $I_{\tau}=1 \forall \tau \leq n$ and $I_{\tau}=0 \forall \tau>n$ iff $A_{0}<\hat{A}$ and $\theta<\frac{c(1-\delta)}{g \delta} \equiv \hat{\theta}$

3. $I_{\tau}=1 \forall \tau \geq t$, 'always invest', iff $\theta \geq \hat{\theta}$

Note that the last path only exists if $c<\frac{g \delta}{1-\delta}$. The areas spanned by these conditions are depicted in Figure 2.1.

Proof: From Lemma 1 it follows immediately that there can only be these three candidate sequences. To determine which of these candidates is the socially optimal, one then employs the following algorithm: Compare the discounted sum of production in case one stops investing in period $\tau$ to the one in case one stops in period $\tau+1$ :

$$
\frac{A_{\tau}}{1-\delta}>(1-c) A_{\tau}+\delta \frac{A_{\tau}+g\left[(1-\theta)+\theta A_{\tau}\right]}{1-\delta} \Rightarrow I_{n}=0 \forall n \geq \tau
$$

The threshold level of technology that is thus never surpassed immediately follows from this inequality:

$$
A_{\tau}>\frac{g \delta(1-\theta)}{c(1-\delta)-g \delta \theta} \equiv \hat{A}
$$

This threshold is very intuitive: the higher the value of the future, the less costly innovation, and the more productive innovation is the longer it is beneficial to keep innovating. As long as $A_{\tau}<\hat{A}$ investments are productive so that the 
social optimal outcome is given by letting $I_{\tau}$ take the value of one as long as $A_{\tau}<\hat{A}$ and zero otherwise.

If the denominator of $\hat{A}$ becomes negative there is no upper bound on technology; this is the case under the following condition:

$$
c(1-\delta)-g \delta \theta<0 \Leftrightarrow \theta>\frac{c(1-\delta)}{g \delta} \equiv \hat{\theta}
$$

To simplify the exposition and because it is uninteresting, we rule out the never invest social optimum by setting $c<\frac{g \delta}{1-\delta}$ so that we have $\hat{A}>A_{0}=1$. This also implies that $c<\frac{g \delta}{1-\delta}$ and so $\hat{\theta} \in(0,1)$.

The economic intuition of these results is that there is either a strictly positive or strictly negative feedback cycle between the level of technology and investment. If it is positive then investing into technology is self-reinforcing and thus the optimal outcome coincides either with the always invest or the never invest scenario. If the feedback cycle is negative, however, then large levels of technology make further investments into technology prohibitively costly. Independent of the trajectory of $I_{\tau}$ up until period $t$, once such level of technology is reached the optimal further trajectory is given by the never invest scenario.

This feedback cycle can be demonstrated by the comparison of the 'never invest' and 'always invest' scenarios. The values follow from simple arithmetics:

$$
\begin{aligned}
& \sum_{\tau=t}^{\infty} \delta^{\tau-t}\left[Y_{\tau} \mid I_{\tau}=0 \forall \tau\right]=\frac{A_{t}}{1-\delta} \\
& \sum_{\tau=t}^{\infty} \delta^{\tau-t}\left[Y_{\tau} \mid I_{\tau}=1 \forall \tau\right]=(1-c)\left[\frac{A_{t}}{1-\delta(1+g \theta)}+\frac{g(1-\theta)}{(1-\delta)[1-\delta(1+g \theta)]}\right]
\end{aligned}
$$

Next, by taking derivatives, we compare the impact of an increase in the level 
of technology, $A_{t}$, on the discounted sum of output in the two scenarios:

$$
\begin{aligned}
\frac{\partial\left(\sum_{\tau=t}^{\infty} \delta^{\tau-t}\left[Y_{\tau} \mid I_{\tau}=0 \forall \tau\right]\right)}{\partial A_{t}} & =\frac{1}{1-\delta} \\
\frac{\partial\left(\sum_{\tau=t}^{\infty} \delta^{\tau-t}\left[Y_{\tau} \mid I_{\tau}=1 \forall \tau\right]\right)}{\partial A_{t}} & =\frac{1-c}{1-\delta(1+g \theta)}
\end{aligned}
$$

Higher levels of technology mean that the cost of innovation is higher as the costs scale proportionally with technology - this is captured by the numerators of the quotients of the two equations above. Insofar as $\theta>0$ there is a counteracting effect in that the future increases of technology are also proportional to the level of technology and therefore scale as well - this is captured by the denominators of the quotients. Intuitively, the positive effect is more likely to be stronger the closer $\theta$ to 1 - in other words, the closer the trajectory of technology in the always invest scenario is to an exponential function with base $(1+g)$.

It is easily calculated which of the two effects is stronger depending on the parameters. And this yields an alternative derivation of $\hat{\theta}$ :

$$
\frac{1-c}{1-\delta(1+g \theta)}>\frac{1}{1-\delta} \Leftrightarrow \theta>\frac{c(1-\delta)}{\delta g}=\hat{\theta}
$$

Referring back to the short discussion above of the extreme values of $\theta=0$ and $\theta=1$ and their correspondence to 'arithmetic' and 'geometric' growth trajectories, we shall henceforth define as 'arithmetic growth' the case of $\theta \leq \hat{\theta}$ and define as 'geometric growth' the case of $\theta>\hat{\theta}$.

Under arithmetic growth, the socially optimal path of investment is to invest up until technology reaches the level of $\hat{A}$ and then not to invest any more. Pushing technology further down the frontier would be self-harming as the cost of innovation is greater than its benefit; the reason being that costs of innovation scale faster with the level of technology than the return of investment. Under arithmetic growth therefore, technology exhibits a similar behaviour as capital in classical macro models: it has a steady state value in which maintenance and investment equilibrate.

Not so under what we call geometric growth: the return on investment into innovation scales at the same rate as the cost of investment and therefore a positive differential survives into eternity. Consequently, the socially optimal 
path of investment is to invest indefinitely. This is clearly how most scholars of economics today would describe technology.

\subsection{Equilibrium Analysis}

We consider only subgame perfect Nash equilibria in grim trigger strategies. As for equilibrium selection, we assume that the aristocrat may choose his preferred pair among all strategy pairs that would induce such an equilibrium.

The focus on grim trigger strategies is motivated by expositional simplicity and it is justified by the following two aspects of the setting. Firstly, switching to the highest tax rate forever and switching to never innovating, respectively, represent the strongest credible punishment options available to the two agents. secondly, punishments in our setup cannot happen by accident which means alternative punishment strategies like two phase strategies, that would allow agents to forgive past deviations of the respective other agent, do not unlock higher efficiency of the equilibrium outcome.

\subsubsection{Geometric Growth $(\theta>\hat{\theta})$}

In the case of geometric growth, the socially efficient outcome is achieved by continual investment into innovation. In a world of grim trigger Nash equilibria, the aristocrat will thus strive to find a strategy pair according to which the serf is just willing to innovate in every period. For that to be the case the serf has to be compensated for the cost of innovation and be motivated not to cheat.

Since taxes cannot exceed $100 \%$ and the decision over innovation is under the discretion of the serf, the minimum utility of the serf will be 0 in equilibrium (the never invest scenario with $T_{t}=1 \forall t$ ). It is therefore immediate that the aristocrat will have to compensate the serf for the cost of innovation, which is $c A_{t}$, if the serf is to innovate. In equilibria with innovation, the tax rate therefore has to be $T_{t}^{*} \leq 1-c$ in all periods $t$.

A putative equilibrium in which the aristocrat plays $T_{t}=1-c$ if the serf has 
played $I_{\tau}=1$ for $\tau<t$ and $T_{t}=1$ otherwise and in which the serf plays $I_{t}=1$ if the aristocrat has played $T_{\tau}=1-c$ for $\tau<t$ and $I_{t}=0$ otherwise, however, would be destroyed by a deviation of the serf: by not investing in period $t$, the serf would increase his current period $t$ utility by $c A_{t}$ and suffer no loss in utility in the following periods. This profitable deviation is made possible by the assumption that the the two agents move simultaneously, so that the aristocrat can only react in the following period.

In order to render such a deviation not profitable, the aristocrat would have to grant the serf a rent which he can threaten to withdraw in the event of a deviation. The discounted sum of the flows of this rent have to be at least as high as $c A_{t}$ in order to provide sufficient incentive to the serf.

If we label such a rent flow as $R_{t} A_{t}$, it is immediate that, from the point of view of the aristocrat, the optimal flow of this rent will grow at the same rate as the serf's payoff to the deviation - which is equal to the rate of technological growth. Formally, we have the following condition on this rent flow:

$$
c A_{t}=\sum_{\tau=t+1}^{\infty} \delta^{\tau-t} R_{\tau} A_{\tau} \forall t
$$

The rent flow thus critically depends on the rate of growth of the technology. We can be more specific on this rate: when $A_{0}=1$, as we assumed above, then in the initial period growth comes from the geometric part of technology in the proportion of $\theta$ and from the arithmetic part of technology in the proportion of $(1-\theta)$ - with the growth rate from period 0 to period 1 being equal to $g$. As the level of technology grows, an ever larger share of further growth comes from the geometric part; in fact, in the limit it completely crowds out the arithmetic contribution to technology. The growth rate of the economy thus falls to and asymptotes $g \theta$ :

$$
\lim _{A_{t} \rightarrow \infty} \frac{\dot{A}_{t}}{A_{t}}=\lim _{A_{t} \rightarrow \infty}\left[\frac{g(1-\theta)+g \theta A_{t}}{A_{t}}\right]=g \theta
$$

From this follows that in the long run the arithmetic part of growth plays a negligible role in the determination of $R_{t}$. And if that is the case, then equation 
(2.25) simplifies considerably and $R_{t}$ becomes a constant $R$ :

$$
c A_{t}=R^{\mathrm{lr}} \delta \frac{A_{t+1}}{1-\delta(1+g \theta)}=R^{\mathrm{lr}} \delta \frac{A_{t}(1+g \theta)}{1-\delta(1+g \theta)} \Rightarrow R^{\mathrm{lr}}=\frac{c[1-\delta(1+g \theta)]}{\delta(1+g \theta)}
$$

This equation only holds in the long run, when the level of technology is very high. Initially the growth rate is higher and therefore a lower share of the future output stream is sufficient to keep the serf from deviating. We can calculate the corridor within which $R_{t}$ is going to move by calculating the hypothetical case of a growth rate of $g$ forever; which is equivalent to the edge case of $\theta=1$ so that we can use equation (2.27):

$$
R^{\min }=\frac{c[1-\delta(1+g)]}{\delta(1+g)}
$$

We conclude that $R_{t}$ monotonically increases over time and moves in a corridor of $\left(R^{\mathrm{min}}, R^{\mathrm{lr}}\right]=\left(\frac{c[1-\delta(1+g)]}{\delta(1+g)}, \frac{c[1-\delta(1+g \theta)]}{\delta(1+g \theta)}\right]$.

We can now formalise the highest possible tax rate that provides a rent flow whose discounted sum is equal to the one period deviation payoff of the serf; we simply define $T_{t}^{*}$ as $1-c-R_{t}$.

From the point of view of the aristocrat, a tax rate regime of $T_{t}^{*}$ provides the highest possible share of the output under the restriction that the serf is induced to innovate. We therefore define the following pair of equilibrium strategies: the aristocrat plays $T_{t}=T_{t}^{*}$ if the serf has played $I_{\tau}=1$ for $\tau<t$ and $T_{t}=1$ otherwise; the serf plays $I_{t}=1$ if the aristocrat has played $T_{\tau}=T_{t}^{*}$ for $\tau<t$ and $I_{t}=0$ otherwise. It remains to be checked under what conditions the introduced strategy pair constitutes a subgame perfect Nash equilibrium.

Consider the serf first: off the equilibrium path the serf expects the aristocrat to play $T_{t}=1$ and his best response to that tax rate is not to innovate, as required.

On the equilibrium path he receives a rent flow of $R_{t} A_{t}$ every period - which he expects to lose given any deviation of his. His only possible deviation is not to innovate which by construction yields the same expected discounted payoff as the equilibrium strategy - so the serf has no incentive to deviate.

Consider now the aristocrat: off the equilibrium path the aristocrat expects 
the serf not to innovate, there is thus no reason for him to constrain his urge to confiscate all production and set $T_{t}=1$, as required.

On the equilibrium path the aristocrat receives a discounted payoff that is higher than $\left(1-c-\frac{c[1-\delta(1+g \theta)]}{\delta(1+g \theta)}\right)\left[\frac{A_{t}}{1-\delta(1+g \theta)}+\frac{g(1-\theta)}{(1-\delta)[1-\delta(1+g \theta)]}\right]$; his actual payoff is higher because the former value is calculated using the upper bound of $R_{t}$. His best deviation is switching to $T_{\tau}=1$ for $\tau \geq t$ which would yield an expected discounted payoff of $\frac{A_{t}}{1-\delta}$ as he expects the serf to stop innovating. The aristocrat will thus not deviate if the parameters of the model are such that:

$$
\left(1-c-\frac{c[1-\delta(1+g \theta)]}{\delta(1+g \theta)}\right)\left[\frac{A_{t}}{1-\delta(1+g \theta)}+\frac{g(1-\theta)}{(1-\delta)[1-\delta(1+g \theta)]}\right] \geq \frac{A_{t}}{1-\delta}
$$

Intuitively, this inequality is more likely to hold the more patient the agents are, the faster technology progresses on the equilibrium path and the more it does so in a geometric fashion; it is less likely to hold the higher the cost of innovation. We can be more specific by isolating $A_{t}$ on the right hand side:

$$
\delta g(1-\theta)(1+g \theta)-c \geq A_{t}\left[c-\delta(1+g \theta)^{2}\right]
$$

The discussion so far can now be consolidated in the following proposition:

\section{Proposition 3 Equilibria under Geometric Growth}

We consider two types of grim trigger Nash equilibria:

- 'no investment equilibrium' in which the aristocrat plays $T_{t}=1$ and the serf plays $I_{t}=0$ for all $t$

- 'continual investment equilibrium' in which the aristocrat plays $T_{t}=1-$ $c-R_{t}=T_{t}^{*}$ if the serf has played $I_{\tau}=1$ for $\tau<t$ and $T_{t}=1$ otherwise and in which the serf plays $I_{t}=1$ if the aristocrat has played $T_{\tau}=T_{\tau}^{*}$ for $\tau<t$ and $I_{t}=0$ otherwise

The existence of these equilibria can be expressed in terms of the cost of innovation:

- $c \in(0, g \delta(1-\theta)(1+g \theta)] \Rightarrow$ both equilibria exist 
- $c \in\left(g \delta(1-\theta)(1+g \theta), \delta(1+g \theta)^{2}\right) \Rightarrow$ the never invest equilibrium exists and the continual investment equilibrium exists if $A_{t} \geq \frac{\delta g(1-\theta)(1+g \theta)-c}{c-\delta(1+g \theta)^{2}}$

- $c \in\left[\delta(1+g \theta)^{2}, 1\right) \Rightarrow$ only the no investment equilibrium exists

Proof: The intervals of $c$ follow immediately from Equation (2.30) and the discussion in the preceding text.

Compared to a world with no aristocrat, the socially optimal outcome is realised for narrower ranges of the parameter values because the decision-maker considers incentive costs of $R_{t}$ which are irrelevant from a social point of view; the economy is therefore potentially loosing efficiency. Yet if the parameter values are such that the aristocrat chooses to induce the serf to innovate then we see technology progressing on the socially optimal path.

Our setup thus replicates the basic tenet of the literature on economic institutions in that extractive institutions are suboptimal because they destroy or dilute incentives to undertake growth enhancing investments. The problem arises from the fact that not only does the person directly concerned with the investment into innovation need to be motivated but also the rent extracting member of the elite; this more complicated incentive structure increases the private costs of innovation over and above the social costs.

\subsubsection{Arithmetic Growth $(\theta \leq \hat{\theta})$}

In the case of arithmetic growth the socially optimal outcome is achieved by continual investment up until technology reaches a certain level and no investment afterwards.

In the chosen framework of subgame perfect Nash equilibria in grim trigger strategies this outcome is not attainable. The reason lies with the fact that the incentive structure is that of a finite sequence of prisoner's dilemmas which precludes co-operation for the same inexorable logic as a finitely repeated prisoner's dilemma. 
Proposition 4 Equilibrium under Arithmetic Growth

The equilibrium under arithmetic growth is for the aristocrat to set $T_{t}=1 \forall t$ and for the serf to set $I_{t}=0 \forall t$.

Proof: We show that an equilibrium with investment into innovation does not exist and proceed in the following four steps:

- There is no equilibrium with investment taking place indefinitely because in that case technology would also grow indefinitely and with it the negative return on investment. Investment has to stop after a finite number of periods.

- Compensation of the serf cannot be deferred to the period after investment into innovation has stopped as this would not violate the incentive compatibility of the aristocrat and hence subgame perfection.

- Investment by the serf cannot take place after compensation has run its course as that would violate the incentive compatibility of the serf and hence subgame perfection.

- The last period in which investment is undertaken and compensation or rent granted cannot be incentive compatible as both aristocrat and serf would want to deviate to full taxation and no investment, respectively.

In this setup, we have a clear policy credibility problem. Both aristocrat and serf would prefer an outcome that involves a finite sequence of investment by the serf which is compensated by some tax break arrangement. We are thus touching on the vast literature on policy credibility: if we included uncertainty over the preferences of the aristocrat one would possibly reach settings in which the ideas of papers such as Backus and Driffill [1985] and Athey et al. [2005] could fruitfully be applied. Even though full credibility is not reached in their setup because some of the assumed uncertainty surrounding the preferences of the committing party remains in existence from the point of view of the other party, certain moves by the committing party can sway expectations of the 
other party and thus partly resolve the credibility issue. In our setting, this could take the form of the serf being uncertain whether the aristocrat has the utility function assumed throughout the paper or an altruistic one that cares about the payoff of the serf as well.

Commitment devices can be constructed, however, more closely within the constraints of the setup. We turn to one such device in the ensuing section.

\subsection{Extension A: inclusive institutions as a com- mitment device to a fixed tax rate}

Suppose the aristocrat had the option to choose, before the game begins, whether or not to install some inclusive institutions. If he chooses not to then the game is the same as in the above section. If he chooses to set up such institutions then this enables him to commit to a fixed tax rate of his choosing - he will, in the game that ensues, not be able to change the tax rate away from this fixed rate.

\subsubsection{Geometric Growth Regime $(\theta>\hat{\theta})$}

If the aristocrat wanted to implement a rent for punishment purposes as in the equilibrium of the preceding section, he would need no such institutions.

We therefore need to consider the alternative only, which is to motivate the serf to innovate by giving him a sufficient stake in future production in cases that the punishment equilibrium is not attainable. The aristocrat would thus effectively grant a constant share of all production to the serf and this share would be enshrined as the complement of the fixed tax rate or $1-T_{\text {fixed }}$. This is how for the purposes of this section we define inclusive institutions.

The aristocrat would want to set $T_{\text {fixed }}$ as high as possible and it is easy to calculate how high is feasible. Write $T_{\text {fixed }}$ as $1-c-\epsilon$ which shows that the serf needs compensation for the investment cost plus a reward which is captured by $\epsilon>0$. Then for the serf to innovate it must hold that his discounted payoff given 
continual investment must be at least as high as his discounted payoff given no investment into innovation.

In order to ease the exposition, suppose for a moment that the aristocrat can vary $\epsilon$ from period to period while the serf expects the current period $\epsilon_{t}$ to stay the same forever, then it follows that:

$$
\epsilon_{t}\left[\frac{A_{t}}{1-\delta(1+g \theta)}+\frac{g(1-\theta)}{(1-\delta)[1-\delta(1+g \theta)]}\right] \geq \frac{\left(c+\epsilon_{t}\right) A_{t}}{1-\delta}
$$

Alternatively, by some rearrangement we have:

$$
\epsilon_{t} \geq \frac{c[1-\delta(1+g \theta)] A_{t}}{g \delta \theta A_{t}+g(1-\delta)}
$$

By definition, however, $\epsilon$ has to be fixed by the aristocrat before the game begins and cannot be adjusted afterwards. For innovation to be always lucrative to the serf, it must therefore be set such that the above equation holds for any value of $A_{t}$ (a sufficient condition). $\epsilon_{t}$ being increasing in $A_{t}$ we thus have ${ }^{6}$ :

$$
\epsilon=\lim _{A_{t} \rightarrow \infty} \epsilon_{t}=\frac{c[1-\delta(1+g \theta)]}{g \delta \theta}>\frac{c[1-\delta(1+g \theta)]}{\delta(1+g \theta)}=R^{\max }
$$

This means that whenever the threatened punishment equilibrium of the previous section is feasible the aristocrat will not set up inclusive institutions. One may perhaps say that motivation by reward is costlier than motivation by punishment or that conditional rents are cheaper than unconditional ones.

With a slight added condition, this result also holds in a setting in which $\epsilon_{t}$ need not be fixed but can be varied over time. In such a setting, the aristocrat is not forced to set $\epsilon$ at the highest level needed over time but can let it increase over time towards that level thus capturing more of the output.

A lower bound on $\epsilon_{t}$ can be derived from Inequality (2.31) by setting $A_{t}$ to the lowest possible value of 1 . Note that this bound is lower than the actual lower bound as in equilibrium the serf will anticipate the increases in $\epsilon_{t}$ and therefore require a higher current period share as opposed to the derivation of Inequality (2.31) which assumes a stable expected $\epsilon_{t}$. But this lower bound is

\footnotetext{
${ }^{6}$ An algebraic note: the relationship holds for all values of $\theta$ since $\epsilon$ is decreasing in $\theta$ and is larger than $R^{\max }$ at $\theta=1$.
} 
still instructive:

$$
\left.\epsilon_{t}\right|_{A_{t}=1}=\frac{c[1-\delta(1+g \theta)]}{g \delta \theta+g(1-\delta)}>\frac{c[1-\delta(1+g \theta)]}{\delta(1+g \theta)}=R^{\max } \text { iff } \delta>\frac{g}{1+g}
$$

For practical purposes it is safe to assume $\delta>0.5$ which covers all admissible values of $g$.

Being thus shown to be more costly, this second mechanism to reach the socially optimal path of continual investment into innovation does not extend the range of parameter values for which the socially optimal path can be reached. Inequality (2.30) still holds. Inclusive institutions are thus both expensive and unnecessary under the regime of geometric growth.

\subsubsection{Arithmetic Growth Regime $(\theta \leq \hat{\theta})$}

In this growth regime one would naively expect the option of setting up inclusive institutions to be a lot more valuable. After all, without it the pair is stuck in a no growth equilibrium precisely because of the lack of a commitment device. Unfortunately, this is not quite so.

Consider again the optimal strategy of the aristocrat given inclusive institutions which again can be written as $T_{\text {fixed }}=1-c-\eta$ where we changed $\epsilon$ to $\eta$ in order to avoid confusion. The serf will innovate in any period in which innovation raises his discounted payoff. The serf will stop to innovate if a last innovation investment would yield a lower discounted payoff than not innovating:

$$
(c+\eta)\left[\frac{A_{t}}{1-\delta}+\delta \frac{g(1-\theta)+g \theta A_{t}}{1-\delta}\right]-c A_{t} \leq(c+\eta) \frac{A_{t}}{1-\delta}
$$

From this we can calculate the threshold for $\eta$ :

$$
\eta \leq \frac{c A_{t}(1-\delta)}{\delta\left[g(1-\delta)+g \theta A_{t}\right]}-c
$$

The intuition is clear: the higher the growth rate, the lower the cost of innovation, the more patient the agents, the more periods the serf will innovate. As to technology we have $\frac{\partial \eta}{\partial A_{t}} \in\left(0, \frac{c(1-\delta)}{g \theta}\right)$ and so the higher the level of technology the higher $\eta$ needs to be to induce the serf to innovate, as required. 
The aristocrat will now optimise over the total number of periods that the serf would choose to innovate given $\eta$, call this number $\hat{T}$. This optimisation has a unique solution as the benefit of increasing $\hat{T}$ by one period is decreasing in $\hat{T}$ while the cost of doing so is increasing in $\hat{T}$. The reason for this is again the arithmetic nature of technology if $\theta \leq \hat{\theta}$.

We proceed to the comparison of the payoff to the aristocrat given inclusive institutions with his payoff without:

$$
(1-c-\eta)\left(\frac{A_{0}}{1-\delta}+\sum_{t=1}^{\hat{T}} \delta^{t} \frac{g(1-\theta)+g \theta A_{t}}{1-\delta}\right) \quad \text { vs } \quad \frac{A_{0}}{1-\delta}
$$

The crux of this solution is evident in the comparison of these terms: the rent granted to the serf will continue to hurt the aristocrat forever, long after it has served its purpose. Under arithmetic growth, inclusive institutions in the sense of a permanent limit in taxes are simply very costly to the aristocrat.

Thinking a bit outside the model there is another crux here: the very credibility of inclusive institutions is problematic. It is clear to all participants that the aristocrat would want to use them as a temporary measure and will try hard to abolish them once growth has run its course - yet in order to do their magic they need to be permanent. This internal inconsistency would in practice have forestalled most attempts towards successfully implementing such institutions.

One can think of slightly more sophisticated tax regimes that would counter this potential commitment problem. One way would be to let the lower tax rate be conditional on past investment behaviour of the serf. In its simplest form this would mean granting the serf a lower tax rate and hence a share of the output for a fixed number of periods after an investment activity.

While this would not materially change the cost of providing the serf enough incentive to invest - there is little scope for arbitrage as the two have the same linear utility function over output and the same time preference - but it would potentially mediate the mentioned commitment issues in a psychological sense by limiting the cost exposure of the aristocrat to a finite number of periods.

In fact, the fixed period tax breaks for foreign direct investment in special investment zones may possibly be seen as an example of such responses. 

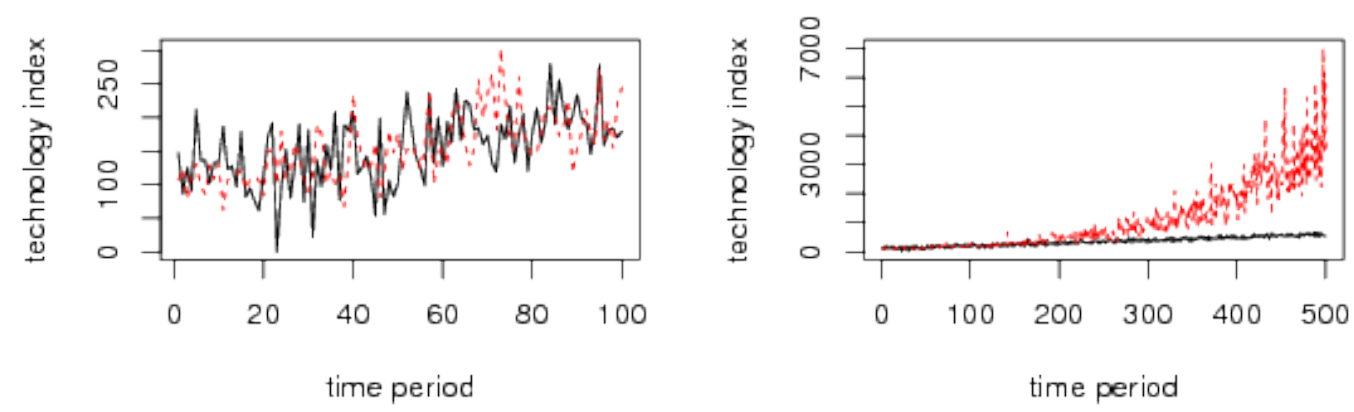

Figure 2.2: This diagram shows two sample paths of technology given continual innovation and one of the two regimes respectively; the dashed and lighter line marking the geometric growth regime $\left(A_{0}^{a}=A_{0}^{g}=100, g=0.00734, a=1\right.$, $\sigma_{g}^{2}=0.25$ and $\left.\sigma_{a}^{2}=50\right)$. When history is not far advanced the two series are clearly difficult to distinguish.

\subsection{Extension B: Uncertainty over the Nature of Technology}

We now introduce uncertainty into the model by augmenting the dynamics of technology by random fluctuations. We do not aim for a complete analysis but rather point towards some of the possible implications. To simplify the exposition, we concentrate on the extreme cases of $\theta=0$ and $\theta=1$.

The trajectories of technology under these two cases are characterised by the following two equations: ${ }^{7}$ :

$$
\begin{array}{llll}
\text { geometric growth: } & A_{t}=A_{t-1}\left(1+g I_{t-1}\right) \mathrm{e}^{\varepsilon_{t}^{g}} & \text { with } & \varepsilon_{t}^{g} \sim N\left(0, \sigma_{g}^{2}\right) \\
\text { arithmetic growth: } & A_{t}=A_{t-1}+a I_{t-1}+\varepsilon_{t}^{a} & \text { with } & \varepsilon_{t}^{a} \sim N\left(0, \sigma_{a}^{2}\right)
\end{array}
$$

Where we have renamed $g$ to $a$ in the arithmetic case to avoid confusion. The levels of $g$ and $a$ as well as of $\sigma_{g}^{2}$ and $\sigma_{a}^{2}$ cannot be compared directly, but they can be chosen such that they induce very similar looking fluctuations. For an example see Figure 2.2.

\footnotetext{
${ }^{7}$ To be precise, one would have to assume that technology cannot fall below a certain positive constant under either regime in order to prevent technology from turning negative or, in the case of Equation (2.38), getting stuck at zero.
} 
To keep things very simple, we assume that, conditional on the growth regime, all parameters are known with certainty; the remaining uncertainty being firstly whether technology is generated by Equation (2.38) or (2.39) and secondly the future realisations of $\varepsilon^{g}$ or $\varepsilon^{a}$. Suppose further that the pair of aristocrat and serf is Bayesian, starts out with some prior assigning probabilities to both regimes and updates this common belief according to the following simple rule.

A sage measures the level and change of technology every period and reports which of the two growth regimes is more compatible with the observation. He decides in favour of the regime whose standard score is closer to zero, that is for which $\left|\frac{\varepsilon_{t}}{\sigma}\right|$ is smaller. Note that, conditional on the regime, $\varepsilon_{t}$ is an observed value in this setup.

The belief of the aristocrat and serf pair can then be represented by the mean of a beta distribution where the output of the sage is transformed to 1 if he reports 'geometric' and 0 otherwise; we label this mean or probability assigned to the geometric case as $p_{g}$. The belief, in period $t$ since the start of time, over the probability of living under the geometric growth regime is thus:

$$
p_{g}=\frac{\alpha_{t}}{\alpha_{t}+\beta_{t}} \text { with } \alpha_{t}=\hat{\alpha}+k \text { and } \beta_{t}=\hat{\beta}+t-k
$$

Where $k$ is the number of time the sages has reported geometric up until and including period $t$ and where $\hat{\alpha}$ and $\hat{\beta}$ parameterise the prior. This is admittedly a very simplified setup: not only is information lost by the discretisation in general but increasingly so as technology advances.

Next, suppose that the sage decides every $n$th period whether to let the game of the two be based on the premise of geometric or on the premise of arithmetic growth. They then play the game, somewhat unrealistically, as if they were in the certainty case of the main model section.

The decision of the aristocrat can be formalised in the following way: denote the aristocrat's payoff given that the pair plays believing in arithmetic growth when the true nature is indeed arithmetic growth as $U_{t}^{\text {aris }}(A \mid a)$; denote his payoff if the pair plays believing in arithmetic growth when the true nature is geometric 
growth as $U_{t}^{\text {aris }}(A \mid g)$ and so on. The respective payoffs are:

$$
\begin{aligned}
& U_{t}^{\text {aris }}(A \mid a)=\frac{1-\delta^{n}}{1-\delta} A_{t}+\delta^{n} E\left[U_{t+n}^{\text {aris }}\left(A_{t}\right)\right] \\
& U_{t}^{\text {aris }}(A \mid g)=\frac{1-\delta^{n}}{1-\delta} A_{t}+\delta^{n} E\left[U_{t+n}^{\text {aris }}\left(A_{t}\right)\right] \\
& U_{t}^{\text {aris }}(G \mid a)=\left(1-\delta^{n}\right) \frac{1-c-R}{1-\delta}\left(A_{t}+\frac{\delta a}{1-\delta}\right)+\delta^{n} E\left[U_{t+n}^{\text {aris }}\left(A_{t}+n a\right)\right] \\
& U_{t}^{\text {aris }}(G \mid g)=\left(1-\delta^{n}\right) \frac{1-c-R}{1-\delta(1+g)} A_{t}+\delta^{n} E\left[U_{t+n}^{\text {aris }}\left(A_{t}(1+g)^{n}\right)\right]
\end{aligned}
$$

The decision-rule of the aristocrat can be formalised as follows:

$$
\left(1-p_{g}\right) U_{t}^{\text {aris }}(A \mid a)+p_{g} U_{t}^{\text {aris }}(A \mid g) \leq\left(1-p_{g}\right) U_{t}^{\text {aris }}(G \mid a)+p_{g} U_{t}^{\text {aris }}(G \mid g) \Leftrightarrow \text { invest }
$$

Where 'invest' is a shorthand for the aristocrat inducing the serf to innovate by granting him a rent through $T_{t}=T_{t}^{*}<1$.

We can further simplify by letting $n \rightarrow \infty$ which renders Equations (2.41) to (2.44) substituted into (2.45) more easily readable:

$$
1 \leq(1-c-R)\left[1+\frac{\delta \frac{a}{A_{t}}}{1-\delta}+p_{g}\left(\frac{1-\delta}{1-\delta(1+g)}-\left[1+\frac{\delta \frac{a}{A_{t}}}{1-\delta}\right]\right)\right]
$$

The interpretation is intuitive: the left-hand-side represents the payoff from the no-investment case while the right-hand-side represents the cost multiplied with the expected reward of the investment case. The latter is the sum of the arithmetic regime reward of the investment case and the probability-weighted uplift to that under the geometric regime.

We can now draw the following simple conclusions from this extension introducing uncertainty:

If $a, g, \sigma_{a}^{2}, \sigma_{g}^{2}$ and $A_{0}$ are chosen such that the fluctuations of the two regimes are rather similar around the initial value of technology $A_{0}$ and if the pair of aristocrat and serf happens to start off with a prior that lets the aristocrat decide not to innovate then this decision is going to have a strong tendency to get perpetuated for want of observations outside the range of similar behaviour of the two regimes. If the true regime is geometric growth, then change towards innovation may come only by some serendipitous discovery or a disaster, i.e. a 
very high or very low $\varepsilon_{t}$, which nudges the trade-off in favour of innovation: by pushing $A_{t}$ far away from $A_{0}$ such discovery would make the regimes distinguishable via the different effect of a change in the base technology on multiplicative and additive errors. The probability of whether or not the road to technological growth will eventually be taken or not will thus be a function of $\sigma_{a}^{2}$ and $\sigma_{g}^{2}$.

The converse is not true: if again $a, g, \sigma_{a}^{2}, \sigma_{g}^{2}$ and $A_{0}$ are chosen such that the fluctuations of the two regimes are rather similar around the initial value of technology $A_{0}$ and the rates of growth are comparatively small then a pair with a prior that induces innovative behaviour faces substantial chance of abandoning the path of innovation for want of clearly observable indications for geometric growth. And once having reverted to the no investment case, it is difficult to start innovating as noted above.

In an informal manner, we have thus argued that, under conditions that plausibly reflect the setting of mankind for most of its history, extractive institutions offering no incentive for innovative behaviour form a near-absorbing state. If, however, innovative behaviour is allowed, by some fortuitous chance, to be pursued long enough for the compound effect of geometric growth to become clearly visible then the investment into innovation case becomes an absorbing state.

Once broken free from insufficient faith in technology, humanity will eventually converge onto a path of constant investment into innovation.

\subsection{Discussion}

In this paper we have aimed to show that at the heart of the the questions of (1) what institutions a society adopts and (2) what trajectory of technological growth it enters lies the perception of the nature of technology.

On a fundamental level, we relate perceptions and policy choices: if technology is viewed as stagnant or potentially growing linearly - or 'arithmetic' as we call it - then an elite that lives off extracting resources from the rest of the populace will not implement growth friendly policies. The reason need not be that these policies yield insufficient rewards, it is that the elite cannot credibly 
commit to reward the efforts that are required by the exploited. A not so obvious corollary is that the perception of technology of the exploited populace is as important as the perception of the exploiting elite.

If a society believes in the promise of exponential - or 'geometric' - growth, however, elites do not stand in the way of growth and instead set up extractive or, if those are not feasible, even inclusive institutions that facilitate investments in innovation. It is important to note the strategic complementarity of growth friendly institutions and the perception of technology.

Going one step further it can be argued that one would not only expect the two to emerge closely together but also that institutions follow beliefs. Applying this idea for instance to the United Kingdom of the post Elizabethan era one may, as with so many cases of laws of the past, assert that the take away message of patent laws is possibly not that they encode a functioning system but rather that they reflect with what measures the elite hoped to improve its situation - the laws should thus be read as testament to the belief in the promise of technological growth.

In a historical perspective, the tipping point for technological advancement comes then not from the movement from extractive to inclusive institutions but from a change of perception by the ruler or ruling class of a society. They need to realise or understand the potential of technological change and find institutional arrangements that, from their perspective, mitigate the dangerous side-effects.

One may interpret the economic rise of China since Deng Xiaoping as both anecdotal evidence to this hypothesis and as a very large scale experiment thereof.

Finally, we argue that - given technology grows indeed in a geometric rather than arithmetic manner - growth friendly institutions are more likely to be adopted as history progresses and more and more decisive observations become available on the returns of investment into technology. It is from this positive feedback cycle that we draw the conclusion that, in the end, growth is the fundamental driver of growth.

The final prediction of the model is one of global convergence. As the potential productivity of workers further outgrows the value of commodities, taxation of market economies becomes ever more attractive. 


\section{Chapter 3}

\section{A critical literature review of the Property Rights Theory of the Firm and the communication of Unprotected Information Assets}

\subsection{Introduction}

For anyone interested in information gathering, processing, storing and so on we live in truly exciting times. Not only is the exponential trend in the development information technology making itself felt across more and more industries previously untouched; and the term of the knowledge worker, human capital, intellectual property and innovation in the centre of many discussions on economic growth and competitiveness; but also there is the emerging ecosystem of cryptocurrencies like Bitcoin that promise to revolutionise the documentation and storage of information, ideas and ownership.

And yet, the currently dominant theoretical framework for the study of organisations, the Property Rights Theory of the Firm, is prima facie agnostic to the role of information as an asset in the economic production process.

One may wonder whether information is truly just like any physical asset. Specifically, one is led to ask whether information is indeed purchasable like other 
assets; the closest equivalent to purchasing physical assets is the purchase of patents, but these cover only a very narrow set of possible information based assets. One is also led to ask whether a strict rivalry assumption is appropriate. In short, information is likely to be in need of special treatment in the framework of Property Rights Theory. And these questions are increasingly pressing as our economies are moving towards being ever more heavily based on information processing and knowledge.

In this survey, we review a recent and emerging literature that employs Cheap Talk in organisational settings where asymmetric and unverifiable information warrants a careful consideration of the allocation of decision-rights. From our point of view, this literature is closest to answering the kind of questions that the presence of unprotected information assets pose in Property Rights Theory. We are going to conclude, however, that the literature so far has not properly answered the question of how the virtual and ephemeral nature of information affects their ownership properties and their implications.

\subsection{Literature review}

\subsubsection{The Property Rights Theory of the Firm}

The property rights theory of the firm may be said to form the basis of our current understanding of the theory of the firm. It in turn grew out of the transaction costs literature that followed Coase [1937] and refined it by providing an explicit mechanism that leads to both costs and benefits of organising economic activity inside organisations rather than arms-length via the market. The essence of the property rights theory of the firm is captured in just two papers: Grossman and Hart [1986] and Hart and Moore [1990].

In Grossman and Hart [1986], transaction costs are made concrete by incentive misalignment arising from dispersed ownership of assets. Building on earlier work of Klein et al. [1978] and Williamson [1979], the starting point is "a situation in which it is prohibitively difficult to think about and describe unambiguously in advance how all the potentially relevant aspects of the production 
allocation should be chosen as a function of the many states of the world" (page 696). In the first period of a two period world, the right to decide in such a situation is then given to the owner of the asset - ownership is thus defined as conferring residual control. In fact, ownership in its usual meaning of control and power indeed arises only if not all future decision-making can be contracted upon beforehand.

The analysis is simplified by letting renegotiation in period two be costless as well as information symmetric, so that actions are contractible ex post and thus in period two an efficient outcome is achieved. The distribution of the realised surplus depends on the distribution of ownership and through this channel discretionary investment activity in period one is sensitive to the ownership structure; where discretionary means that the investment is not contractible. This is why ownership matters.

The central insight is that ownership is allocated such that the ex-ante investment decisions are distorted as little as possible. The boundary of firms therefore reflects the sensitivity of ex-ante investment decisions to the bargaining over the ex post surplus. Suppose there are two assets that require investment, then if heavy investment in one of these yields more ex post output than heavy investment in the other or moderate investment in both then the owner of this one asset will acquire the other asset as well; the party whose high level of investment is important is given high bargaining power. If investment in both assets is about equally important then non-integration will dominate.

In Hart and Moore [1990], the focus is widened from control being exercised completely by one party or the other party (in the sense of atomistic assets for single agent use), to one where assets are used by more than one party and hence one can refer to an owner and the workers he employs to work with this asset. The meaning of residual control rights is interpreted in this setting as meaning that the owner can selectively exclude agents from the use of the asset.

As in Grossman and Hart [1986], the solution concept is based on the idea that agents trade or assign ownership such that the ex-ante investment decisions are distorted as little as possible, so that they are second-best. Some common wisdom and stylised facts of actual ownership structures emerge naturally out of the model: if only one person invests, then he should own all assets; com- 
plementary assets should be owned by one person or entity; if an asset affects the marginal benefit of only one agent then he should own it; and if an agent is indispensable to an asset then he should own it irrespective of whether he invests into the connected venture or not. The latter point is a strong departure, or important extension, from the results of Grossman and Hart [1986].

Information is not considered as separate asset in this model, but rather as a part or a byproduct of investments ${ }^{1}$. Asymmetric information is mentioned, however, as one of potential barriers to efficient ex-post negotiation in both papers.

In general terms, certain types of information are clearly assets as they can be put to use such that output is generated; all technological know-how falls into this category. At the same time, information is a complicated asset in the framework of the Property Rights Theory because residual control rights are not necessarily granted by society in the sense of the literature. Hart and Moore [1990] define the residual control as the right to exclude agents from the use of the asset: while this is by construction possible when it comes to information embodied in well defined and enforced patent rights, it is far from clear how less well protected assets will be handled in this framework.

In more general terms, the Property Rights Theory of the firm applies only to protected assets and little attention has gone to the effect of the presence of unprotected assets on the equilibrium and its welfare properties.

Some of this attention has gone into how private and non-verifiable information, hence unprotected once revealed, can be incorporated into the productive use of another asset. The literature on this question centres on a principal that takes investment decisions and has no direct access to some useful piece or pieces of information that reside with an agent or scattered over multiple agents. The solution concepts draw on the insights into communication equilibria concerning non-verifiable information with partial incentive alignment of Crawford and Sobel [1982] and the question of allocated decision-rights in the spirit of Grossman and Hart [1986] and Hart and Moore $[1990]^{2}$. We turn to and focus on this

\footnotetext{
${ }^{1}$ Which in Hart and Moore [1990] are restricted to investments into human capital.

${ }^{2}$ There are other approaches in the literature to the question of how unprotected information may be traded; of those touching upon property rights only those have been included in this survey that are explicitly grounded in Property Rights Theory and that draw on commu-
} 
literature now.

\subsubsection{A single biased agent with soft private information}

The first paper to explore the implications of having the control over a physical asset separate from the control over pieces of information crucial to the productive use of said asset - and using cheap talk following Crawford and Sobel [1982] - is Dessein [2002]. This paper, and indeed the whole ensuing literature that is the focus of this essay, departs from the classical property rights literature in assuming that ownership of the physical asset and information asset are not grouped ex-ante in order to minimise ex-ante distortions; instead, communication mechanisms are explored that aim to alleviate the consequences of thus separated control.

The setting consists of a principal and an agent where the principal selects a project from a set of projects of whose profitability the agent is privately informed; the principal therefore seeks to utilise the agents's knowledge. The principal is initially in control of some asset or resource critical to any of the projects and then has to decide how to place this control between the agent and herself. It is assumed that projects or actions cannot be contracted upon and so the principal is left with only two options regarding this allocation of decision rights: either let the agent report on his information and then decide herself; or fully delegate the choice of the project to the agent.

The allocation of decision-rights may be interpreted as the analogue of or substitute for the allocation of ownership rights.

The agent reporting his information is cheap talk as communication is costless and the information non-verifiable or soft. Cheap talk à la Crawford and Sobel [1982] is possible because apart from the agent's constant bias the preferences of agent and principal move in unison depending on the private information of the agent so that, firstly, different types of agents have different preferences over the principal's actions and, secondly, agent and principal preferences are not completely opposed.

nication of non-verifiable information; as an example of those not included we refer to Anton and Yao [2002]. 
More formally, projects differ along only one dimension and the chosen project can therefore be represented by a scalar number $y$. The utility of the principal $U_{p}$ and the utility of the agent $U_{a}$ both depend on this choice $y$ and a random number $m$ with known distribution with support $[-L, L]$ whose realisation is observed by the agent alone:

$$
\begin{aligned}
& U_{P}(y, m)=U_{P}(m, m)-l_{P}(|y-m|) \\
& U_{A}(y, m)=U_{A}(m+b, m)-l_{A}(|y-(m+b)|)
\end{aligned}
$$

where $b>0$ represents the agent's bias and $l_{P}(\cdot)$ and $l_{A}(\cdot)$ are convex functions whose derivative is zero at the origin. Under delegation, the agent thus implements $y=m+b$ and therefore the payoff to the principal is $U_{p}=U_{P}(m+b, m)-$ $l_{P}(b)$.

Without delegation, the agent and the principal engage in communication and one can apply the framework of Crawford and Sobel [1982]: according to their Theorem 1, communication takes the shape of a partition of $[-L, L]$ and the agent reporting which of these partitions $m$ falls into; the intuition is that by partitioning the message state and thus the response of the principal into discrete steps the agent is forced to choose between an over-reaction and an under-reaction by the principal. One can think of this added noise as destroying an infinite loop of correcting the message by principal and counter-correcting the message by the agent. Partitions are defined by a boundary condition that disallows arbitrage by letting the agent be indifferent between two partitions should the value of $m$ fall on the boundary of these ${ }^{3}$.

The surprising result is that for $m$ being uniformly distributed it can be shown that whenever a cheap talk equilibrium is possible (i.e. the bias not too large) then it is better for the principal to delegate the decision-making. She thus either makes an uninformed decision or delegates - consulting the agent and deciding based on his report does not occur.

The intuition behind this result is that the intervals that make up the partition are increasingly large as one moves towards the higher end point. This is due to the aforementioned indifference condition: Let $a_{0}$ and $a_{1}$ define the first interval

\footnotetext{
${ }^{3}$ In terms of equilibrium selection, Dessein [2002] argues that agent and principal will coordinate on the ex-ante Pareto superior equilibrium if this exists (which is always the case if $m$ is uniformly distributed). It is given by the equilibrium with most partitions.
} 
and $a_{1}$ and $a_{2}$ the second; then the principal will set $y_{1}=\left(a_{0}+a_{1}\right) / 2$ and $y_{2}=\left(a_{1}+a_{2}\right) / 2$ for the respective intervals and thus at $m=a_{1}$ the agent must be indifferent between $y_{1}$ and $y_{2}$. This means that $a_{1}=\left(y_{1}+y_{2}\right) / 2-b$ needs to hold which in turn translates into the following:

$$
a_{2}-a_{1}=a_{1}-a_{0}+4 b
$$

By induction one can thus conclude that the interval lengths grow linearly by 4b. This is intuitive, as the agent has a positive bias and thus needs to add more noise for recommending large projects; in other words and a bit loosely, without costly noise that distorts his information the agent cannot make his recommendation of a large project credible. And with large increases in the interval lengths the average length of an intervals is necessarily high; so high that the principal is on average further away from her optimal project under communication than she would be by delegation.

One can interpret this result as a replication of the finding of Hart and Moore [1990] that complementary assets should be owned by one agent. By deferring the decision-right to the agent, the principal is effectively moving the ownership of her assets to the agent who also owns the information asset. Even though investment decisions are prima facie absent from Dessein [2002] the choice of the project serves the same fundamental purpose of creating a first period decision space on which the second period outcome depends.

More importantly, the communication equilibrium can be interpreted as a transfer of ownership over the information asset from agent to principal. While the framework of the Property Rights Theory assumes the transfer of ownership to be lossless, in the world of unverifiable information and divergent incentives such transfer incurs costs in the form of distortions. Dessein [2002] can therefore be understood as a probe into the relaxation of the lossless ownership transfer assumption of Property Rights Theory. Viewed from this angle, the paper's main result points to the hypothesis that agents holding key information are indispensable agents in the sense of Hart and Moore [1990].

There are papers that raise questions very similar to Dessein [2002]. Among these are Alonso [2008] and Harris and Raviv [2005]. The latter for instance examine a setting that differs only in that the principal also holds private infor- 
mation regarding the profitability of the potential projects. While the general implications are similar, the fact that complementary information is split in its initial ownership means that neither agent is necessarily indispensable as in Dessein [2002].

The tentative conclusion regarding information as indispensable asset does not hold, however, in more general and complex settings; when information is dispersed among more than one agent, for instance, costly transfers of ownership will occur if the pieces of information are sufficiently complimentary in the generation of output. It is to such settings that we now turn.

\subsubsection{Multiple agents and horizontal versus vertical com- munication}

The first paper to consider the implications of information assets being dispersed over more than one agent in the setting discussed in this survey is Alonso et al. [2008]. In particular, the authors study the setting of a multi-divisional organisation consisting of two divisions named $j \in\{1,2\}$ and, potentially, a headquarters. Profits of the organisation are given by:

$$
\begin{aligned}
& \pi=\pi_{1}+\pi_{2} \\
& \pi_{j}=K_{j}-\left(d_{j}-\theta_{j}\right)^{2}-\delta\left(d_{j}-d_{-j}\right)^{2}
\end{aligned}
$$

where $d_{j} \in \mathbb{R}$ are the decision variables of the organisation and $\theta_{j}$ are random variables which represent pieces of information local to the divisions and so only available to the respective division manager; they are uniformly distributed with support $\left[-s_{j}, s_{j}\right]$, with $s_{j}>0$. We can thus interpret the decision variable $d_{j}$ as adapting the offering of the organisation to the idiosyncrasies of market of division $j$ which is captured by $\theta_{j}$.

$\delta \geq 0$ captures the degree to which there are gains from coordinating the decisions $d_{1}$ and $d_{2}$ concerning the two divisions; this may be motivated by productivity gains from standardising products, more synergy potentials etc. For expositional simplicity, the authors set $K_{1}=K_{2}=0$.

If ownership could be transferred without cost then the local information of 
division managers would go to headquarters eliminating the information asymmetry. Headquarters would then implement the first best solution by aiming at maximising total profit:

$$
d_{j}^{*}=\frac{(1+2 \delta) \theta_{j}+2 \delta \theta_{-j}}{1+d \delta}
$$

which collapses to $d_{j}^{*}=\theta_{j}$ for $\delta=0$ and approaches $d_{j}^{*}=d_{-j}^{*}=\left(\theta_{1}+\theta_{2}\right) / 2$ as $\delta$ goes to infinity. Via the parameter $\delta$ the setup thus spans all degrees of the tradeoff between adaptation to division-specific market demands and coordination on a uniform product.

For $\delta=0$ the profit function of the headquarters is a simplified version of the principal's utility function in Dessein [2002] with $U_{P}(m, m)=K_{j}, l_{P}(x)=x^{2}$ and $\theta_{j}$ distributed uniformly. This more specific form allows farther-reaching analytical manipulations that we shall come to now ${ }^{4}$.

The agent's preferences are set up differently in that the bias is not a constant added to the optimum of the organisation but shift towards the 'own' division's contribution to the total profit of the company; more specifically, the preferences of the manager $j$ are $\lambda \pi_{j}+(1-\lambda) \pi_{-j}$ with $\lambda \in[0.5,1]$.

Actions are non contractible; more specifically, the organisation can only commit to allocating decision rights ex-ante. Similarly to Dessein [2002], the organisation can choose between the options of delegation, referred to in the context of this paper as decentralisation, and centralisation in which the headquarters decides herself.

Communication takes place in either option: when managers have the right to decide on the $d_{j}$ themselves they send a message to each other, named 'horizontal communication' by the authors, while they send a message to headquarters in the other case, this is named 'vertical communication'.

Decision-making given posterior expectations takes the following forms. Under centralisation, the headquarters follows Equation (3.6) with $\theta_{j}$ replaced by $E\left(\theta_{j} \mid m_{1}, m_{2}\right)$ where $m_{j}$ stands for the message sent by the manager of division

\footnotetext{
${ }^{4}$ Compare to the worked out example for uniform distributions of the sender's signal in Crawford and Sobel [1982] which has become the prime reference point for subsequent research; arguably due to its better tractability.
} 


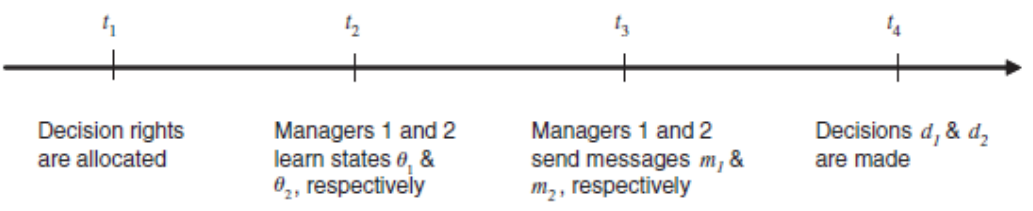

Figure 3.1: We reproduce the time line from the figure in the original paper; this is Figure 1 in Alonso et al. [2008].

$j:$

$$
d_{j}^{C}=\frac{(1+2 \delta) E\left(\theta_{j} \mid m_{1}, m_{2}\right)+2 \delta E\left(\theta_{-j} \mid m_{1}, m_{2}\right)}{1+d \delta}
$$

Under decentralisation one needs to account for the divergent preferences of the managers as well as as the different information structure: now $\theta_{j}$ is known while $d_{-j}$ is a random variable. One arrives at the following:

$$
d_{j}^{D}=\frac{\lambda \theta_{j}+\delta E\left(d_{-j} \mid \theta_{j}, m_{1}, m_{2}\right)}{\lambda+\delta}
$$

Substituting the decision-making structure of the other manager one can reduce the expression to messages and $\theta$ s only:

$$
d_{1}^{D}=\frac{\lambda}{\lambda+\delta} \theta_{j}+\frac{\delta}{\lambda+\delta}\left(\frac{\delta}{\lambda+2 \delta} E\left(\theta_{1} \mid \theta_{2}, m_{1}, m_{2}\right)+\frac{\lambda+\delta}{\lambda+2 \delta} E\left(\theta_{2} \mid \theta_{1}, m_{1}, m_{2}\right)\right)
$$

and likewise for $d_{2}^{D}$.

When incentives are perfectly aligned, that is $\lambda=0.5$, then managers report the value of the observed $\theta$ truthfully so that both the decisions under centralisation (Equation (3.7)) and under decentralisation (Equation (3.9)) collapse to the profit maximising decision outlined in Equation (3.6). With $\lambda>0.5$, however, preferences between observers and decision-makers diverge and therefore managers have an incentive to misrepresent their observations.

We follow the authors in examining the incentive structure of misrepresentation before moving to the equilibrium discussion.

Considering centralisation first, it is straightforward to see that headquarters places too much weight on coordination between divisions relative to local adaptation from the point of the view of the division managers. If $\theta_{1}>0$ for instance, 
manager 1 would expect the full information case decision of headquarters $d_{1}^{*}$ to lie on $\left(0, \theta_{1}\right)$ because the unconditional expectation of $\theta_{2}$ is zero and manager 1 receives no information concerning $\theta_{2}$; in particular, he would expect $d_{1}^{*}$ to be lower than the value of $d_{1}$ that maximises his expected payoff because headquarters puts less weight on the adaptation to the local conditions of division 1 than manager 1 would want her to. Intuitively therefore, he has an incentive to exaggerate his information so as to push headquarters' belief over the value of $\theta_{1}$ higher. This desire to move the belief of the headquarters to a more extreme value can be formalised in the (misguided) posterior of headquarters that maximises the expected payoff of manager $j$ :

$$
\theta_{j}+b_{C} \theta_{j} \text { where } b_{C}=\frac{(2 \lambda-1) \delta}{\lambda+\delta}
$$

Clearly, for $\lambda>0.5$ we have $b_{C}>0$ as well as $\frac{\partial b_{C}}{\partial \lambda}>0$ and $\frac{\partial b_{C}}{\partial \delta}>0$. The more biased managers are and the greater the need for coordination, the more extreme or exaggerated managers would want the posterior beliefs of headquarters to be regarding the $\theta$ pertaining to their division. Note, however, that incentives are aligned in the case of $\theta_{j}=0$.

In the case of decentralisation, one can again derive the posterior belief over the value of $\theta_{j}$, this time held by manager $-j$, which maximises the expected payoff of manager $j$. This takes the value of $\theta_{j}+b_{D} \theta_{j}$ where $b_{D}=\frac{(2 \lambda-1)(\lambda+\delta)}{\lambda(1-\lambda)+\delta}$. As in the case of centralisation, for $\lambda>0.5$ it holds that $b_{D}>0$ so that the manager again exaggerates his information and increasingly so as the bias increases, $\frac{\partial b_{D}}{\partial \lambda}>0$. The rationale, however, is different: since manager $j$ sets $d_{j}$ himself there is no loss in the adaptation to local conditions from his point of view, instead there is perceived a coordination deficit as manager $-j$ puts too much relative weight on the local adaptation for division $-j$. Note also that $\frac{\partial b_{D}}{\partial \lambda}>\frac{\partial b_{C}}{\partial \lambda}$, so that the incentive to exaggerate increases more sharply in the decentralised setting; the intuition being that not only does the bias of the manager sending the message increase but also the recipient manager's whom the first wants to influence.

But the decisive insight is that $\frac{\partial b_{D}}{\partial \delta}<0$. The reason is that, again from the point of view of manager $j$, manager $-j$ puts too little weight on coordination and higher values of $\delta$, i.e. higher need for coordination, reduce this divergence of preferences. One can therefore expect that the relative performance of horizontal 
communication compared to vertical communication improves as coordination becomes more important.

This is indeed the case. Similar to Crawford and Sobel $[1982]^{5}$, in the communication equilibrium the space of $\left[-s_{j}, s_{j}\right]$ cut up into intervals that increase in length as one moves away from zero ${ }^{6}$. Defining one such interval $i$ by $\left[a_{j, i-1}, a_{j, i}\right]$ the arbitrage condition between intervals can be written as:

$$
a_{j, i+1}-a_{j, i}=a_{j, i}-a_{j, i-1}+4 b a_{j, i}
$$

Notice the similarity to Equation (3.3). The parameter $b$ stands for the above defined $b_{C}$ or $b_{D}$ depending on whether the communication is embedded into the centralised or decentralised organisational setup; the incentive to misrepresent one's signal in order to induce more extreme posterior beliefs at the receiver of the message therefore directly translates into noisy communication.

Expected profits of the organisation under the two regimes centralisation and decentralisation are then derived by substituting the posterior beliefs resulting from the communication subgame into the decision-making logic captured by Equations (3.7) and (3.9), respectively.

The resulting relative payoffs of the two regimes define regions of dominance in the parameter space spanned by $\lambda$ and $\delta$. We reproduce the resulting plot from the paper in Figure 3.2.

The intuition is as follows. When managers exhibit only a very small bias, i.e. low values of $\lambda$, then decentralisation is always the preferred option, even when the need for coordination is very high. The reason is that horizontal communication improves as the need for coordination increases. In a sense, the coordination deficiency of decentralisation is healed endogenously, while the exogenous medicine of centralisation suffers from increasingly noisy communication.

\footnotetext{
${ }^{5}$ The difference to Crawford and Sobel [1982] lies in the facts that (1) there are two senders instead of one in the game of Alonso et al. [2008] and (2) that the incentives of sender and receiver are completely aligned in the case of $\theta_{j}=0$. The latter point is also responsible for there being no finite upper bound on the number of intervals that can be supported in equilibrium.

${ }^{6}$ Equilibrium selection is again based on an efficiency argument, the organisation is assumed to coordinate on the equilibrium with the most detailed communication and hence highest expected profit.
} 


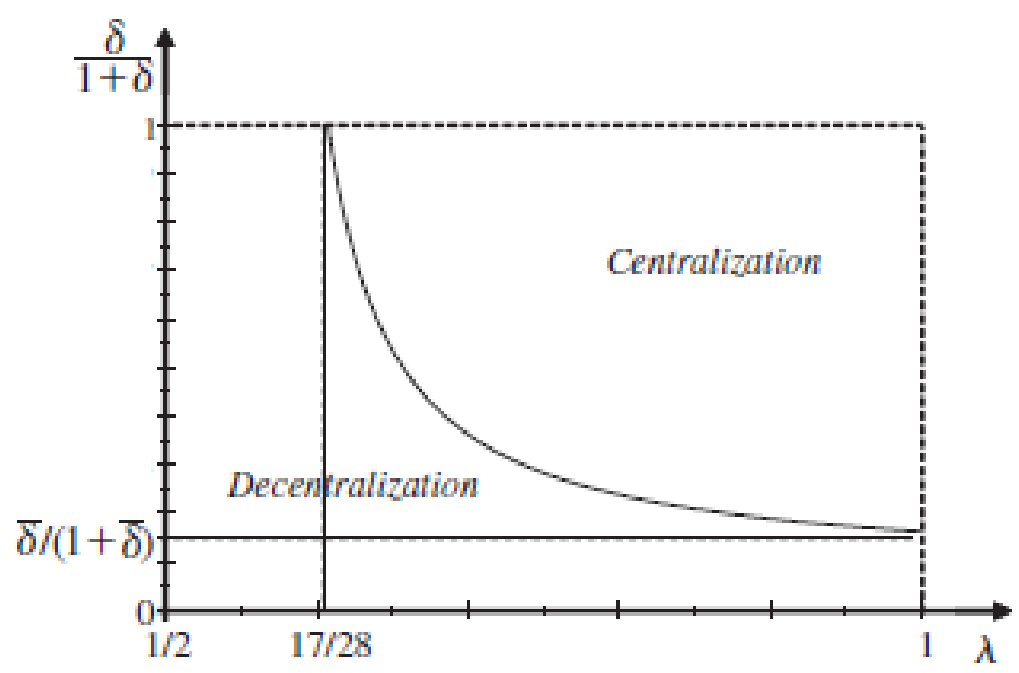

Figure 3.2: We reproduce the regions of dominance in the parameter space spanned by $\lambda$ and $\delta$; this is Figure 6 in Alonso et al. [2008].

When the need for coordination is very small, i.e. low values of $\delta$, then likewise decentralisation is always preferred. The reason is that the bias of managers has no adverse effect on local adaptation under decentralisation but worsens local adaptation under centralisation because the latter relies on communication which suffers under high bias.

When both the need for coordination and the bias of managers is high then centralisation performs better. This is for two reasons: as discussed above, vertical communication suffers less from high bias than horizontal communication $\left(\frac{\partial b_{D}}{\partial \lambda}>\frac{\partial b_{C}}{\partial \lambda}\right)$; second, managerial bias distorts the decision-making away from coordination whereas headquarters does not suffer from this (again compare Equations (3.7) and (3.9)).

Independently and concurrently to Alonso et al. [2008], Rantakari [2008] developed a very similar model. The chosen setup is essentially the same as in Alonso et al. [2008], only the scope of the analysis is broadened in two directions and narrowed in one direction. In particular, the implication of asymmetries between the divisions is explored in depth and more governance structures are considered. In the main body of the paper, Rantakari [2008] does not allow for varying degrees of bias of the managers, holding this constant at the maximum at $\lambda=1$ in the above introduced notation. 
The profit function of the organisation is given by:

$$
\begin{aligned}
& \pi=\pi_{1}+\pi_{2} \\
& \pi_{j}=K_{j}-k_{j}\left[\left(d_{j}-\theta_{j}\right)^{2}-r_{j}\left(d_{j}-d_{-j}\right)^{2}\right]
\end{aligned}
$$

where $K_{j}=0$ for convenience in this paper as well. This profit function is the same as Alonso et al. [2008] for $k_{j}=k_{-j}$ and $r_{j}=r_{-j}$, i.e. if divisional asymmetries are removed. The distributions of the $\theta_{j}$ and the information structure of the game is the same as in Alonso et al. [2008].

The set of available governance structures is extended to include partial centralisation and directional authority which respectively refer to headquarters deciding on the variable $d_{j}$ of the centralised division $j$ whereas the other decides on $d_{-j}$ herself and to one of the divisions subordinated to the other division in that one division manager holds all decision rights.

By marginalising out the idiosyncratic parts of the scopes of the two papers, the results of the equilibrium analysis can be checked for consistency. The lengths of the communication intervals discussed in detail above shall serve as an example here. They are reported in the following format by Rantakari [2008]:

$$
\left|a_{j, i+1}-a_{j, i}\right|-\left|a_{j, i}-a_{j, i-1}\right|=\frac{4}{\varphi_{i}^{d e c}}\left|a_{j, i}-E_{i} \theta_{j}\right| \text { with } \varphi_{i}^{d e c}=\frac{r_{j}\left(1-r_{-j}\right)}{1-r_{j}}
$$

where the notation of the boundaries is changed to the one introduced above in Equations (3.3) and (3.11). As above, we have $E_{i} \theta_{j}=0$ in equilibrium; and further we have $\left.\frac{1}{\varphi_{i}^{\text {dec }}}\right|_{r_{j}=r_{-j}}=\frac{1}{r_{j}}$ which is equal to $\left.b_{D}\right|_{\lambda=1}=\frac{1+\delta}{\delta}$ because for $k_{j}=k_{-j}$ and $r_{j}=r_{-j}$ we can transform the profit function of Rantakari [2008], see (3.12), into the one of Alonso et al. [2008], see (3.4), by setting $\frac{r_{j}}{1-r_{j}}=\delta$. As expected, the results coalesce as one moves to the ground of common assumptions.

From the perspective of Property Rights Theory of the Firm, these two papers can be seen as probing into the relaxation of yet another assumption, namely that the use of assets is rival. While the case of the usage of information being completely non-rival is trivial in that ownership does not matter then, the horizontal communication case is interesting because it moves towards non-rival 
as managers retain separate decision-rights and at the same time communicate (in a distorted manner).

The two discussed papers show that even very high output interdependencies do not lead to the allocation of residual control rights over the information assets to a single agent if the pieces of information are sufficiently close to being non-rival. This is a strong qualification of the standard implications of Property Rights Theory.

As a side note, the comparison of Alonso et al. [2008] and Rantakari [2008] is a nice illustration of serendipity in the progress of science. By any measure, except for the degree of bias of the managers, Rantakari [2008] offers the more complete and wider ranging analysis; equilibrium relationships and values are derived in a unified framework across all governance structures and performance comparisons extend from a preference mapping onto the parameter space and verbal intuition to analytical dissection of the equilibrium profit into losses due to biased decision-making and due to strategic communication. Yet the central result of Alonso et al. [2008], namely that for relatively low bias decentralisation dominates centralisation even for very high needs of coordination, was missed in Rantakari [2008]. One may perhaps even say that this is the only insight of the union of two papers that is surprising and thus adds to general knowledge. Rantakari [2008] was very close: the critical intuition driving this result is mentioned $^{7}$ and in an extension, he considers varying degrees of bias. In the pertaining figure, one can basically see the dominance of decentralisation for symmetric divisions with the naked eye, see Figure 3.3.

One may wonder whether a sparser setup with fewer degrees of freedom in the profit function would have made the result more likely to be discovered.

\footnotetext{
7"However, as we increase the dependency of the divisions further, the quality of decisionmaking starts eventually improving. The reason for this is that as the divisions become highly dependent, the agents have no option but to coordinate if they want to maximize the profitability of their divisions." See p. 20. He elaborates further on p. 26: "We can see that while the quality of communication is always higher under centralized authority than that under decentralized authority, this difference is decreasing in the importance of coordination to either division."
} 


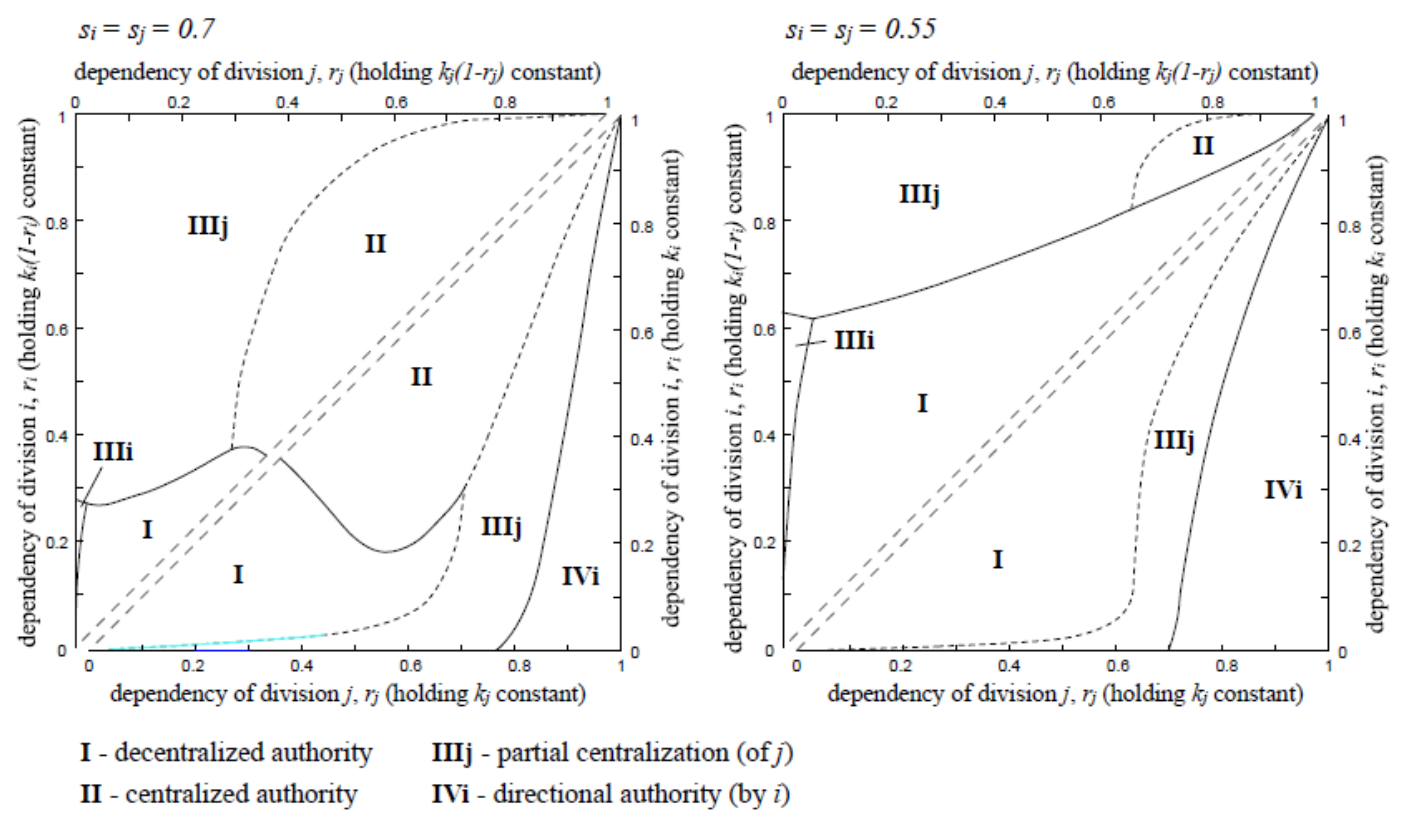

Figure 3.3: These figures show the efficient organisational structure given different interdependency levels between divisions. The left diagram shows the relative performance for $\lambda=0.7$ while the diagram on the right shows the relative performance for $\lambda=0.55$. This is Figure 8 in Rantakari [2008]. For a comparison with Alonso et al. [2008] focus on the dashed diagonal lines running from bottom left to top right of the respective diagrams as they chart the case of symmetric divisions with a varying degree of interdependence. We see that for $\lambda=0.7$ and high coordination needs, centralisation beats decentralisation, while the diagram for $\lambda=0.55$ shows that decentralisation all but dominates centralisation. In Figure 3.2, the dashed diagonal lines would show as two vertical lines crossing the $x$ axis at 0.55 and 0.7 , respectively. The dominance of decentralisation for low bias is then evident. 


\subsubsection{Endogenous managerial bias}

The decisive factor determining to what extent the use of nonverifiable information is rival or non-rival is the degree to which the incentives of agents diverge. It is therefore natural to turn to the question of how this degree is determined. One approach to answering this question can be found in Dessein et al. [2010] who move from exogenously given biases of agents towards question of organisational design that yield biases endogenously as the outcome of a trade-off between competing demands on the incentive structure of agents.

More precisely, Dessein et al. [2010] is concerned with the question of how an organisation should be designed if (1) parts of the value chain of its business units have synergetic potential through standardisation across units, (2) potential standardisation decisions have to be delegated to a functional manager by headquarters, and (3) standardisation may hurt sales by ruling out adaptation to local market conditions.

Strategic communication in the form of cheap talk recedes in importance as tailoring incentive structures takes centre stage.

The organisation in question consists of two business units which in turn consist of two business processes, production and sales; production has synergetic potential while sales does not. Headquarters has two options to choose from: non-integration, i.e. function as a financial holding with two operatively separate business units let by business unit managers, or integration, i.e. hire a third manager to oversee production and standardisation decisions.

The profit function of the organisation takes the following general form:

$$
\pi=\sum_{i} R_{i}-\sum_{i} C_{i}=\sum_{i}\left(v e_{r i}-\Delta_{i} I+\varepsilon_{c i}\right)-\sum_{i}\left(C-v e_{c i}-\frac{k}{2} I+\varepsilon_{c i}\right)
$$

where $i \in\{1,2\}$ indexes the business units, $R$ and $C$ stand for revenue and cost, respectively. $e_{c i}$ and $e_{r i}$ denote effort levels of the managers where under non-integration business unit manager $i$ decides on both $e_{r i}$ and $e_{c i}$ while under integration $e_{c 1}$ and $e_{c 2}$ are decided by the functional manager. $v$ denotes the productivity of effort. $I$ takes the value of 1 if under integration the functional manager decides to standardise and 0 otherwise; synergy shows in a cost reduc- 
tion of $k$ which is drawn from a uniform distribution with support $[0, K]$ while the non-adaptation costs lower revenues in market $i$ by $\Delta_{i}$ where the latter takes the value of $\Delta>0$ with probability $p$ and 0 otherwise. $k$ is known to the functional manager while the business unit managers know their respective $\Delta_{i} . \varepsilon_{r i}$ and $\varepsilon_{c i}$ represent environmental volatility drawn from normal distributions with mean 0 .

Profit maximisation thus requires solving two challenges: first, inducing effort exertion on behalf of the managers who face private costs of effort of quadratic form $\frac{e^{2}}{2}$; and second, setting the right incentives for the standardisation and adaption trade-off for the functional manager. Note that the second challenge only materialises in the case of integration.

In the models reviewed so far the principal or headquarters was unbiased and took decisions herself in the case of centralisation. Centralisation in the context of Dessein et al. [2010] takes the form of integration and introduces a third selfcentred agent into the picture and therefore the challenge or question is not only how to transmit the private information of agents towards the central decisionmaker but also how to let this new third party make use of this information to the benefit of the organisation.

Inducing effort is achieved by sharing the surplus, by assumption in the way of linear contracts. In this regard, additive mean zero normal disturbances are a convenient way of expressing the decision-making logic of agents with constant absolute risk aversion. The basic rationale behind output volatility and risk-averse agents, however, appears to be that such setup implies that giving the functional manager a stake in volatile revenues, which are untouched by his exerted effort, is costly in that compensating lump sum transfers from agent to organisation have to be lower than the expected compensation from this stake. In order to solve the second challenge it is nonetheless beneficial for the organisation to give the functional manager a stake in the revenue flow. Without such stake the manager would only care about the cost side and completely disregard the adaptation loss stemming from standardisation.

The driving assumption behind the need for this stake is that standardisation is non-verifiable, which means the functional manager has complete discretion in his decision-making. The first rationale given is that it is difficult to judge 
for an outsider to what extent standardisation has taken place and whether it is was surplus generating in expectation or not; while this argument feels a bit forced the second relates convincingly to the overall setup by referring to a sort of verification and decision-making overload which will have prompted the delegation of this activity to a third party agent in the first place and thus renders verification impractical.

In a first-best world, standardisation is of course implemented iff $k>\Delta_{1}+$ $\Delta_{2}$. Under non-integration, it is never implemented while under integration the functional manager will implement standardisation iff $k>\frac{\alpha_{r}^{F}}{\alpha_{c}^{F}}\left(\Delta_{1}+\Delta_{2}\right)$ which intuitively means that the functional manager will use the first-best threshold in his decision-making only if his incentives are balanced equally across revenues and costs as in the organisational profit function.

Completely balancing these incentives and thus achieving first-best decisionmaking regarding standardisation is very costly, however, as both raising the stake of the functional manager in revenues $\alpha_{r}^{F}$ to the level that represents the optimal level of stake in costs under the effort inducing aspect is costly for the reason discussed above while lowering the stake in costs $\alpha_{c}^{F}$ obviously leads to prima facie inefficiently low effort levels $e_{c i}$. Dessein et al. [2010] show that at the optimum the balance is tilted towards excessive standardisation and thus managerial bias is endogenously determined and consciously chosen by the organisational designer.

Communication of $\Delta_{1}$ and $\Delta_{2}$ takes the form of a very simple cheap talk game: since at $\Delta_{i}=0$ there is no incentive conflict between sender and receiver (business unit manager and functional manager, respectively) $\Delta_{i}=0$ is truthfully reported; at $\Delta_{i}=\Delta$ the sender has an incentive to overstate $\Delta_{i}$ which he cannot do because the highest value $\Delta_{i}$ can take is $\Delta$ and hence also this number is truthfully reported.

In a sense this is a logical next step of simplification from Alonso et al. [2008] who introduced the complete incentive alignment of agent and principal for the case of the variable of interest taking the value of zero.

The question of communication appears in earnest only in an extension to the baseline model. The extension changes $\Delta_{i} \in\{0, \Delta\}$ to $\Delta_{i} \in\left\{\Delta_{L}, \Delta_{H}\right\}$ with both $\Delta_{L}$ and $\Delta_{H}$ greater zero. This way truthful communication is not 


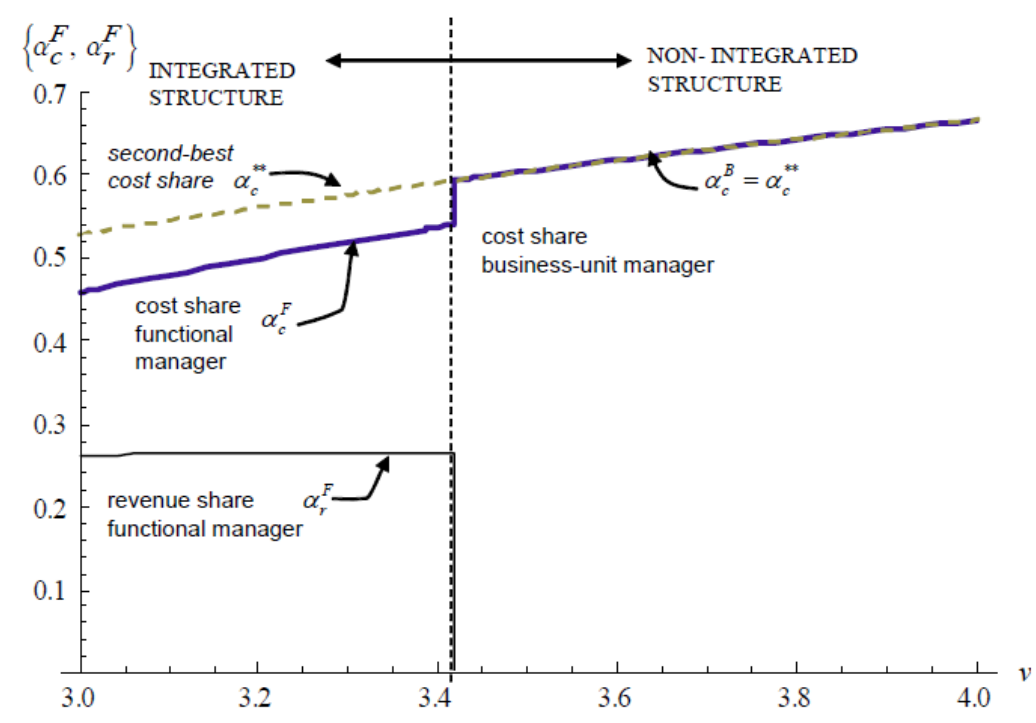

Figure 3.4: This diagram charts incentive costs depending on the importance of effort $v$. Note that $\alpha_{c}^{F}>\alpha_{r}^{F}$ for all relevant values of $v$ so that we have excessive standardisation in expectation; $\alpha_{c}^{F}$ is lower than the second best stake $\alpha_{c}^{* *}$ so that the functional manager exerts too little effort; these two observations mark the optimal trade-off between effort and alignment. Note lastly that for sufficiently high value of effort synergies from integration are not pursued. This is Figure 2 in Dessein et al. [2010]. 
possible in the setting discussed so far as the business unit managers would always have an incentive to overstate the value of $\Delta_{i}$. To overcome this difficulty in communication, business unit managers must be given a stake in cost savings so as to better align their incentives with the interests of the overall organisation.

The result of this new setup is that the organisational designer either (1) gives business unit managers a stake in cost savings and softens their effort incentives - very similar to the case of the functional manager - so as to induce communication or (2) does not give such incentives and leaves communication incredible altogether. Not surprisingly, further divergence of incentives makes the integration case less attractive as adapting incentives to ease communication flows harms effort incentives.

From the perspective of classical Property Rights Theory, asset ownership in this setup clearly should go altogether to the functional manager as his investment choice (effort levels can be interpreted as such) and his residual control over standardisation together are central to the outcome and it is not clear what the headquarters is for. From a more abstract perspective, the setup of the model is one of lumped and inseparable assets (effort levels and information) in which the costs of asset transfer in the form of communication are created because their elimination would make the distribution effects of the irrevocably wrongly allocated overall ownership (to headquarters instead of the functional manager) overly expensive.

In a sense, the departure from the standard case of costless asset transfer is thus motivated with the departure from the standard case that all assets can be transferred.

Dessein et al. [2010] take a large step towards explaining where diverging interests between managers in different roles and between managers and shareholders stem from and why they may be efficient in a second best sense. The setup, however, is to some degree unsatisfactory in that it introduces uncertainty into the payoffs of the organisation purely to make revenue share incentive contracts costly. And this is problematic both from a methodological point of view and from an empirical point of view.

Methodologically, this shifts the burden of being an ad hoc assumption from the question of why managers have biases to question of why providing incentives 
to them should be costly. The chain of causality is extended, but its beginning is only a little less ad hoc and its choice clearly motivated by the effect it has on the model outcomes. Empirically, the relationship between risk and incentives is not as clear cut as a naive reading of Dessein et al. [2010] suggests. At the latest since Prendergast [2002] it is known that the degree of delegation is related to the risk of the activity carried out by a firm and hence cannot be factored out as exogenous when relating risk and incentives. Due to this endogeneity, it is not so clear empirically whether such a negative trade-off exists between risk and the cost of incentives.

Similar to the close relationship between Alonso et al. [2008] and Rantakari [2008], there is a close relationship between Dessein et al. [2010] and Rantakari $[2013]^{8}$.

Rantakari [2013] expands the scope by letting the organisational designer choose the degree of interdependence between the divisions or their 'operational integration' rather than assuming this parameter to be exogenous. In the notation of Dessein et al. [2010], the designer thus would have been given a trade-off schedule or menu of values of $K$ and $\Delta(K)^{9}$. The scope is simplified by reducing the number of divisions to two and making them symmetric which also reduced the complexity of the revenue share incentive contracts to the degree in which they are based on the performance of the manager's own division or the performance of the overall organisation. Exertion of work effort is reinterpreted as managerial investment into information acquisition.

The main finding of the paper can be summarised as follows. When the environment is more volatile in the sense the divisional private information has greater variance and hence greater importance in the overall profit function then organisations tend to be structured in a decentralised way with incentives focused on divisional performance. This relationship between decentralisation and environmental volatility is due to the endogenously chosen degree of interdependence between divisions which is reduced when volatility is higher. This is to be expected since greater dispersion of local adaption parameters increases the cost of aligning divisions and with a fixed trade-off schedule over $K$ and $\Delta(K)$

\footnotetext{
${ }^{8}$ Further variants of these models include that of Friebel and Raith [2007].

${ }^{9}$ We are free to translate Rantakari [2013]'s setup also as $\Delta$ and $K(\Delta)$ as Rantakari [2013] assumes a strictly monotonous trade-off schedule.
} 
the optimal level of interdependence should drop in a well behaved system ${ }^{10}$. The above mentioned open questions regarding the results of Dessein et al. [2010] apply to this paper as well; and the concern that an ad hoc assumption is simply moved to a higher level of complexity applies as well to the way that interdependence between divisions is introduced.

Lumping of inseparable assets can take different forms from the one discussed in these two papers. The simples such lumping is the ownership over two pieces of information; we are turning to one such case now.

\subsubsection{Career concerns induced communication equilibria}

Ozbas [2005] is an interesting paper because it arrives at a very different motivational concrete setup from the papers above even though on an abstract level his setup can be seen as an extension of Dessein [2002]. The agent of Ozbas [2005] does not only own information regarding the the project asset but also regarding his own ability. The interesting twist added here is that the transfer of information assets is not only costly, it is also only possible when there is competition between agents in a dynamic setup.

To be precise, Ozbas [2005] studies a two period setting in which managers report the quality of the respective projects they sponsor. Quality can either be high, $R_{H}$, or low, $R_{L}$, and managers are of two types, good and bad ( $g$ and $b$, respectively). Manager types differ in the sense that bad managers only find and sponsor low quality projects while good managers find good projects with probability $\mu \in(0,1)$.

After the managers report the quality, headquarters allocates the investment budget to fund projects based on the information in the reports; the investment budget is assumed to be smaller than the would be required to fund all projects. Managers prefer having their projects funded over not having them funded and prefer having good projects funded. Headquarters maximises the expected payoff from the chosen projects.

\footnotetext{
${ }^{10} \mathrm{On}$ a side note, it is interesting to see the cheap talk theory to advance: while equilibrium selection had been handled informally based on intuitive efficiency considerations in the papers reviewed so far, Rantakari [2013] is able to refer to Chen et al. [2008] for an equilibrium refinement leading to minimised information loss.
} 


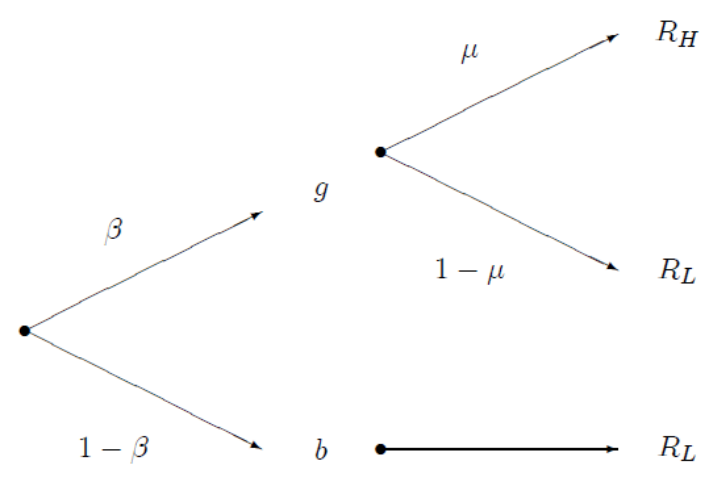

Figure 3.5: This diagram charts the possible project outcomes that good and bad managers may have originally entitles Managerial Talent and Project Outcomes. From the perspective of headquarters, the prior probability of a manager being of the good type is $\beta \in(0,1)$

Ozbas [2005] also deviates from the previous papers by not not using a variant of the Crawford and Sobel [1982] simplified example as his model of cheap talk. Rather, cheap talk arises from the following three characteristics of the setup ${ }^{11}$ :

1. The reports of the managers are soft or non-verifiable as well as costless.

2. In the first of the two periods, incentives of principal and agent are neither completely aligned nor completely opposed as good managers with low quality projects may want to signal their type by truthfully reporting the low quality. Their rationale is that if foregoing funding today by such truthful reporting raises the likelihood of getting funded in the future then only managers who expect to have a high quality project in the future with positive probability will have an incentive to truthfully report and therefore headquarters will indeed raise the likelihood of funding such managers in the second round because their posterior belief over whether the manager is good or not rises from $\beta$ to $1^{12}$.

3. From the previous point follows that good managers with low quality projects and bad managers have different preferences over the actions of

\footnotetext{
${ }^{11}$ Interestingly, Ozbas [2005] does not name the communication in his model cheap talk and even though he includes Crawford and Sobel [1982] in his references he does not cite them in the body of the paper.

${ }^{12}$ The seemingly innocuous and rather ad hoc assumption that managerial utility increases in the profitability of the overseen projects is thus crucial to the working of the model.
} 
the principal; while good managers may in equilibrium prefer the principal not to fund them in the first period and change her beliefs, bad managers want the principal to fund their projects.

Cheap talk is thus induced by career concerns. The theme of organisational design is then based on this setup in the form of varying the number of managers that are competing for funding. The background to this is that the more managers there are, the more patient a good manager needs to be in order for the logic of point 2 above to work. Centralisation or integration thus trades off economies of scope that allow the organisation to concentrate its funding on good managers and diseconomies of scope that make it more difficult to identify good managers.

Based on this finding, Ozbas [2005] explores, to some degree, ideas such as job rotation, rigid divisional capital budgets and depth of hierarchies.

This paper develops the bare minimum version of his setup idea. The model makes do with the lowest possible variability in project and managerial quality as well as the lowest possible number of periods. It should therefore possibly be interpreted as a proof of concept of a certain approach rather than a finished direction of the literature. Richer payoff structures and a richer setting of managerial types would allow deeper probing questions to be answered in a nuanced way as well testing the robustness of the results.

\subsection{Discussion of future avenues for research}

In the preceding section we aimed to show how Cheap Talk as a modelling device can be applied to shed light on the implications of unprotected information assets in the framework of the Property Rights Theory of the Firm. We have documented the diversity of motivational setups in the approaches as well as their connections from the point of view of classical Property Rights Theory.

There appears to be an exciting interplay between structure and uncertainty in the environment, business processes within the organisation, its incentive structures, and its communication flows. We now argue that the literature has only taken its first tentative steps and that most questions are still unresolved. 
In particular, we review three aspects that we think deserve revisiting on behalf of the community: (1) several enriching aspects of the principal agent setting that were introduced in early papers of the literature have been cut away in ensuing papers; (2) the effects of a dynamic setting have been largely left out of the analyses; (3) giving further structure to the question of dynamic settings, agents have scarcely been considered as people with long term career concerns. We review these aspects in turn.

Of the aspects whose examination was started and has not been continued we mention two. Alonso [2008] explores the effects of delegating tasks to the agent that can be either substitutes or complements. This interaction of activities has been translated into setting of more than one agent solely as standardisation synergies. One would expect to find further insight by generalising the multiagent setup to include multi-type activity interaction as well.

A second such lost feature of the setup is private information residing with the principal as in Harris and Raviv [2005]. While one may argue that keeping the setup lean and simple allows for sharper results and clears the view for the important insight (compare the discussion of Alonso et al. [2008] and Rantakari [2008] above), a subsequent check for the robustness of the attained results with regards to such simplifications appears reasonable.

As for the effects of a dynamic setting, we draw on Baker et al. [1999] who examine a repeated principal agent setting where, depending on where private information resides, either the principal builds a reputation for not overriding the informally delegated decision-rights of the agent or the agent builds a reputation for using the received decision-rights in an appropriate manner. Baker et al. [1999] do not consider communication, however, and one would expect the latter to play an important role in such informal delegation. Yet possibly the only paper to move dynamic settings into the focus of the considered literature is Alonso and Matouschek [2007] which embeds a simple variant of one of the oneshot models of Crawford and Sobel [1982] into an infinitely repeated game setting with a long lived principal and a sequence of short lived agents. Yet, as Baker et al. [1999] illustrate, the precise setup of private knowledge and commitment power can tilt the outcome of such a setting into different directions; the role and effect of strategic communication of soft information should therefore be considered to still be an open question. 
A further dynamic aspect of organisation is that they can fail. And yet, to the best of our knowledge, there is no paper that considers the possibility of bankruptcy ${ }^{13}$. One can imagine for instance that small companies with a high probability of failure (like startups) whose structure is such that the efforts of an employee significantly influences this probability naturally leads to more aligned incentives and thus better communication.

Linked to the above, one can imagine that even in more conventional organisational settings dysfunctional communication and decision-making that severely lowers the survival likelihood of the organisation is limited by some equilibrium selection mechanism building on the collective interest of the members of the organisation.

Lastly, one can argue that agents are people with a future, and that they have careers that they care for and which they develop. Ozbas [2005] has spearheaded this idea in the field of communication between headquarters and managers and assignment of decision-rights. Taking up the idea of Alonso et al. [2008] one may wonder, however, whether the addition of horizontal communication in his setting may attenuate the incentive problems faced by headquarters in the many managers case.

One may further conjecture that the empirically observed large payoff differentials between levels of seniority are deliberately designed to boost the incentive aligning effects of career concerns underlying the model of Ozbas [2005].

Career concerns can also be framed in terms of informal evaluations of the performance of colleagues. Similar to the examined setting of evaluating projects, one may again have heterogeneous partial incentive alignment with headquarters. If such setting is then embedded into an overlapping generations model we would expect interesting relationships to emerge. In such a model, one could then also explore the effects of horizontal versus vertical performance evaluations as well as activity interactions.

On a more fundamental level, we want to argue that the literature is missing the abstract view we aimed to show as unifying theme in the above discussions. It is our belief that it is going to be more fruitful to examine the implication of asset classes like information that are potentially partially unprotected and

\footnotetext{
${ }^{13}$ The paper that possibly comes closest is Holthausen and Rønde [2004], but bankruptcy is confined to one contained player in the organisational setup.
} 
partially non-rival in the framework of classical Property Rights Theory rather than to focus on examining the logic of the setups that are chosen to illustrate and motivate the analysis of individual papers. The current impression is that the literature is stuck in niche applications due to its focus on exactly these motivational setups.

To give a concrete example, realising that distorted communication is effectively a cost of transferring assets naturally leads to the question what other mechanisms may, in concert with distorted communication or on their own, make the transfer of information assets costly. And that question would lead to connections to themes such as Chinese whispers or the cost of learning to make sense of information - compare for instance Garicano [2000].

\subsection{Conclusions}

The fundamental insights of the surveyed literature can be summarised in two simple points.

When information as an asset is unprotected, the transfer of its ownership rights can be costly due to distortions in the communication that stem from misaligned incentives. In the framework of Property Rights Theory, ownership is defined as having residual control which in the case of information takes the form of decision-rights. The immediate implication is that the allocation of ownership and decision rights with the least ex-ante distortion is different.

The second fundamental insight is that information assets may be non-rival to some degree. The implication of this is hat non-integration may be favoured also in circumstances that in the traditional view of assets would clearly have called for an integrated organisational structure.

One may perhaps argue that the literature is a replication of the old adage of "knowledge is power" following Bacon in a new form: key information is the asset that makes agents indispensable in the sense of Hart and Moore [1990].

The contribution of this paper has been to systematically structure and review the papers in this area and to have put them into the perspective of prop- 
erty right theory of the firm. It has been shown that the general thrust of theirs can be interpreted as the first part of the solution to a the weak treatment of unprotected information assets in classical the property right theory of the firm. Finally, this paper has pointed out which directions for the literature can be derived from this interpretation.

As a final word one may add that a further piece of potential extensions would be to explicitly widen the scope from private organisations to organisations and institutions in general. Other parts of organisational economics have successfully been applied to organisations such as government agencies, see Garicano and Posner [2005] as an example. 


\section{Bibliography}

D. Acemoglu. A simple model of inefficient institutions. The Scandinavian Journal of Economics, 108(4):515-546, 2006.

D. Acemoglu and J. Robinson. Why Nations Fail: The Origins of Power, Prosperity, and Poverty. Crown Publishing Group (NY), 2012.

D. Acemoglu and J.A. Robinson. Political losers as a barrier to economic development. The American Economic Review, 90(2):126-130, 2000.

D. Acemoglu and J.A. Robinson. Economic backwardness in political perspective. American Political Science Review, 100(01):115-131, 2006.

D. Acemoglu, S. Johnson, and J.A. Robinson. The colonial origins of comparative development: An empirical investigation. The American Economic Review, 91(5):1369-1401, 2001.

D. Acemoglu, P. Aghion, and F. Zilibotti. Distance to frontier and vertical integration. Journal of the European Economic Association, 1:630-38, 2003.

D. Acemoglu, S. Johnson, and J.A. Robinson. Institutions as a fundamental cause of long-run growth. Handbook of Economic Growth, 1:385-472, 2005.

D. Acemoglu, P. Aghion, and F. Zilibotti. Growth, development, and appropriate versus inappropriate institutions. Technical report, Working Paper, 2006.

D. Acemoglu, R. Griffith, P. Aghion, and F. Zilibotti. Vertical integration and technology: theory and evidence. Journal of the European Economic Association, 8(5):989-1033, 2010. 
P. Aghion and P. Howitt. A model of growth through creative destruction. Econometrica, 60(2):323-51, 1992.

Y. Algan and P. Cahuc. Inherited trust and growth. The American Economic Review, pages 2060-2092, 2010.

R. Alonso. Shared control and strategic communication. Memo, Northwestern University, 2008.

R. Alonso and N. Matouschek. Relational delegation. The RAND Journal of Economics, 38(4):1070-1089, 2007.

R. Alonso, W. Dessein, and N. Matouschek. When does coordination require centralization? The The American Economic Review, 98(1):145-179, 2008.

P. Anand, G. Hunter, and R. Smith. Capabilities and well-being: evidence based on the sen-nussbaum approach to welfare. Social Indicators Research, 74(1): 9-55, 2005.

J.J. Anton and D.A. Yao. The sale of ideas: Strategic disclosure, property rights, and contracting. The Review of Economic Studies, 69(3):513-531, 2002.

A. Asoni. Protection of property rights and growth as political equilibria. Journal of Economic Surveys, 22(5):953-987, 2008.

S. Athey, A. Atkeson, and P.J. Kehoe. The optimal degree of discretion in monetary policy. Econometrica, 73(5):1431-1475, 2005.

D. Backus and J. Driffill. Inflation and reputation. The American Economic Review, pages 530-538, 1985.

G. Baker, R. Gibbons, and K.J. Murphy. Informal authority in organizations. Journal of Law, Economics, and Organization, 15(1):56-73, 1999.

L. Barseghyan and A. Guerdjikova. Institutions and growth in limited access societies. Journal of Economic Theory, 146(2):528-568, 2011.

K. Basu. Gender and Say: a Model of Household Behaviour with Endogenously Determined Balance of Power. The Economic Journal, 116(511):558-580, 2006. 
G.S. Becker. A Theory of the Allocation of Time. The Economic Journal, pages 493-517, 1965.

G.S. Becker. A theory of marriage: Part I. The Journal of Political Economy, 81(4):813-846, 1973.

G.S. Becker. A theory of social interactions. The Journal of Political Economy, 82(6):1063-1093, 1974a.

G.S. Becker. A Theory of Marriage: Part II. The Journal of Political Economy, 82(2):S11-26, 1974b.

G.S. Becker. A Treatise on the Family. Cambridge: Harvard University Press, 1981.

T.C. Bergstrom. A fresh look at the rotten kid theorem-and other household mysteries. The Journal of Political Economy, 97(5):1138-1159, 1989.

T. Bragstad. The Private Provision of a Public Good - The Significance of Thresholds. University of Oslo Mimeo, 1991.

E. Brown and Y. Zhang. Is volunteer labor part of household production? evidence from married couples. Review of Economics of the Household, pages $1-29,2012$.

M. Browning. Love, Betrayal and Commitment. Oxford University Mimeo, 2009.

N. Bruce and M. Waldman. The Rotten-Kid Theorem meets the Samaritan's Dilemma. The Quarterly Journal of Economics, 105(1):155-165, 1990.

E. Brynjolfsson and A. McAfee. Race against the machine: How the digital revolution is accelerating innovation, driving productivity, and irreversibly transforming employment and the economy. Digital Frontier Press, 2011.

M. Cervellati, P. Fortunato, and U. Sunde. Hobbes to rousseau: Inequality, institutions and development. The Economic Journal, 118(531):1354-1384, 2008.

Ying Chen, Navin Kartik, and Joel Sobel. Selecting cheap-talk equilibria. Econometrica, 76(1):117-136, 2008. 
A. Cigno. Marriage as a commitment device. Review of Economics of the Household, 10(2):193-213, 2012.

R.H. Coase. The nature of the firm. Economica, 4(16):386-405, 1937.

T. Cowen. The Great Stagnation: How America Ate All The Low-Hanging Fruit of Modern History, Got Sick, and Will (Eventually) Feel Better. Dutton Adult, 2011.

J.C. Cox, D. Friedman, and S. Gjerstad. A tractable model of reciprocity and fairness. Games and Economic Behavior, 59(1):17-45, 2007.

V.P. Crawford and J. Sobel. Strategic information transmission. Econometrica, pages 1431-1451, 1982.

J. B. De Long and A. Shleifer. Princes and merchants; european citz growth before the industrial revolution. Journal of Law and Economics, 36, 1993.

W. Dessein. Authority and communication in organizations. The Review of Economic Studies, 69(4):811-838, 2002.

W. Dessein, L. Garicano, and R. Gertner. Organizing for synergies. American Economic Journal: Microeconomics, 2(4):77-114, 2010.

M. Dufwenberg. Marital investments, time consistency and emotions. Journal of Economic Behavior \& Organization, 48(1):57-69, 2002. ISSN 0167-2681.

M. Dufwenberg and G. Kirchsteiger. A theory of sequential reciprocity. Games and Economic Behavior, 47(2):268-298, 2004. ISSN 0899-8256.

W. Easterly and R. Levine. Africa's growth tragedy: policies and ethnic divisions. The Quarterly Journal of Economics, 112(4):1203-1250, 1997.

A. Falk and U. Fischbacher. A theory of reciprocity. Games and Economic Behavior, 54(2):293-315, 2006. ISSN 0899-8256.

E. Fehr. On the economics and biology of trust. Journal of the European Economic Association, 7(2-3):235-266, 2009.

G. Friebel and M. Raith. Resource allocation and firm scope. 2007. 
O. Galor and D.N. Weil. The gender gap, fertility, and growth. Technical report, National Bureau of Economic Research, 1993.

O. Galor and D.N. Weil. From malthusian stagnation to modern growth. The American Economic Review, 89(2):150-154, 1999.

L. Garicano. Hierarchies and the organization of knowledge in production. The Journal of Political Economy, 108(5):874-904, 2000.

L. Garicano and R.A. Posner. Intelligence failures: An organizational economics perspective. Journal of Economic Perspectives, pages 151-170, 2005.

J. Geanakoplos, D. Pearce, and E. Stacchetti. Psychological games and sequential rationality. Games and Economic Behavior, 1(1):60-79, 1989. ISSN 0899-8256.

R.J. Gordon. Is u.s. economic growth over? faltering innovation confronts the six headwinds. Technical report, National Bureau of Economic Research, 2012.

M. Gradstein. Institutional traps and economic growth. International Economic Review, 49(3):1043-1066, 2008.

S. Grossbard. Independent individual decision-makers in household models and the new home economics. In J.A. Molina, editor, Household Economic Behaviors. Springer, New York, 2010.

S. Grossbard and S. Mukhopadhyay. Children, spousal love, and happiness: an economic analysis. Review of Economics of the Household, pages 1-21, 2012.

S.J. Grossman and O. Hart. The costs and benefits of ownership: A theory of vertical and lateral integration. The Journal of Political Economy, pages 691-719, 1986.

L. Guiso, P. Sapienza, and L. Zingales. Alfred marshall lecture social capital as good culture. Journal of the European Economic Association, 6(2-3):295-320, 2008.

R.E. Hall and C.I. Jones. Why do some countries produce so much more output per worker than others? The Quarterly Journal of Economics, 114(1):83-116, 1999. 
M. Harris and A. Raviv. Allocation of decision-making authority. Review of Finance, 9(3):353-383, 2005.

O. Hart and J. Moore. Property rights and the nature of the firm. The Journal of Political Economy, pages 1119-1158, 1990.

G.D. Hess. Marriage and Consumption Insurance: What's Love got to do with it? The Journal of Political Economy, 112(2):290-318, 2004.

C. Holthausen and T. Rønde. Cooperation in international banking supervision. 2004.

F. Huang. The coevolution of the economic and political development from monarchy to democracy. International Economic Review, 53(4):1341-1368, 2012.

D.S. Johnson. Team Behavior in the Family: An Analysis of the Rotten Kid Theorem. Bureau of Labor Statistics, 1990.

E. Jones. The European miracle: environments, economies and geopolitics in the history of Europe and Asia. New York: Cambridge University Press, 2003.

E. Kalai and M. Smorodinsky. Other solutions to Nash's bargaining problem. Econometrica, 43(3):513-518, 1975.

B. Klein, R.G. Crawford, and A.A. Alchian. Vertical integration, appropriable rents, and the competitive contracting process. Journal of Law and Economics, 21(2):297-326, 1978.

S. Knack and P. Keefer. Does social capital have an economic payoff? a crosscountry investigation. The Quarterly Journal of Economics, 112(4):12511288, 1997.

K.A. Konrad and K.E. Lommerud. Family policy with non-cooperative families. The Scandinavian Journal of Economics, 97(4):581-601, 1995.

K.A. Konrad and K.E. Lommerud. The bargaining family revisited. Canadian Journal of Economics/Revue canadienne d'économique, 33(2):471-487, 2000.

K.A. Konrad and K.E. Lommerud. Love and taxes mand matching institutions. Technical report, lCEPR Discussion Paper, 2008. 
M. Kremer. Population growth and technological change: one million bc to 1990. The Quarterly Journal of Economics, 108(3):681-716, 1993.

A.O. Krueger. Virtuous and vicious circles in economic development. The American Economic Review, pages 351-355, 1993.

R. La Porta, F. Lopez-De-Silane, A. Shleifer, and R.W. Vishny. Trust in large organizations. The American Economic Review, 87(2):333-38, 1997.

D. Leece. Testing a theoretical model of mortgage demand on united kingdom data. Technical report, Citeseer, 2004.

E. Ligon. Dynamic bargaining in households (with application to Bangladesh). Working Paper, 2011. URL Available at SSRN: http://ssrn.com/abstract=1776810 or http://dx.doi.org/10.2139/ssrn.1776810.

X. Liu. Optimal dynamic path of effort on marriage: differences between arranged and love marriages. Applied Economics Letters, 14(1):49-52, 2007.

S. Lundberg and R.A. Pollak. Separate spheres bargaining and the marriage market. The Journal of Political Economy, 101(6):988-1010, 1993.

S. Lundberg and R.A. Pollak. Bargaining and distribution in marriage. The Journal of Economic Perspectives, 10(4):139-158, 1996.

S. Lundberg and R.A. Pollak. Efficiency in marriage. Review of Economics of the Household, 1(3):153-167, 2003.

T.R. Malthus. An essay on the principle of population. J. Johnson, London, 1798.

M. Manser and M. Brown. Marriage and household decision-making: A bargaining analysis. International Economic Review, 21(1):31-44, 1980.

M.B. McElroy and M.J. Horney. Nash-bargained household decisions: Toward a generalization of the theory of demand. International Economic Review, 22 (2):333-349, 1981.

J. Mokyr. The lever of riches: Technological creativity and economic progress. New York: Oxford University Press, 1990. 
K. Nordblom. Cohabitation and marriage in a risky world. Review of Economics of the Household, 2(3):325-340, 2004.

D.C. North. Structure and change in economic history. 1981.

D.C. North. Institutions, institutional change, and economic performance. Cambridge University Press, 1990.

D.C. North and R.P. Thomas. An economic theory of the growth of the western world. The Economic History Review, 23(1):1-17, 1970.

D.C. North and R.P. Thomas. The rise of the western world: A new economic history. New York: Cambridge University Press, 1973.

O. Ozbas. Integration, organizational processes, and allocation of resources. Journal of Financial Economics, 75(1):201-242, 2005.

S.L. Parente and E.C. Prescott. Monopoly rights: A barrier to riches. The American Economic Review, pages 1216-1233, 1999.

R.A. Pollak and M.L. Wachter. The Relevance of the Household Production Function and its Implications for the Allocation of Time. The Journal of Political Economy, 83(2):255-277, 1975.

N. Powdthavee. I cant smile without you: Spousal correlation in life satisfaction. Journal of Economic Psychology, 30(4):675-689, 2009.

C. Prendergast. The tenuous trade-off between risk and incentives. The Journal of Political Economy, 110(5):1071-1102, 2002.

M. Rabin. Incorporating fairness into game theory and economics. The American Economic Review, 83(5):1281-1302, 1993. ISSN 0002-8282.

H. Rantakari. Governing adaptation. The Review of Economic Studies, 75(4): 1257-1285, 2008.

H. Rantakari. Organizational design and environmental volatility. Journal of Law, Economics, and Organization, 29(3):569-607, 2013.

J.A. Robinson. Equity, institutions and the development process. Nordic Journal of Political Economy, 32:17-50, 2006. 
D. Rodrik, A. Subramanian, and F. Trebbi. Institutions rule: The primacy of institutions over geography and integration in economic development. Journal of Economic Growth, 2004.

D. Romer. Advanced Macroeconomics, 3rd edition. McGraw-Hill, 2006.

P. Romer. Endogenous Technological Change. The Journal of Political Economy, 5(XX):1002-1037, 1990.

J. D. Sachs and A. Warner. Economic reform and the process of global inlegration. Brookings Papers on Economic Activity 1997, 1:1, 1995.

P.A. Samuelson. Social indifference curves. The Quarterly Journal of Economics, 70(1):1-22, 1956.

P.G. Sekeris. Endogenous elites: power structure and patron-client relationships. Economics of Governance, 12(3):237-258, 2011.

A. Shleifer and R.W. Vishny. Corruption. The Quarterly Journal of Economics, 108(3):599-617, 1993.

M. Si. Intrafamily bargaining and love. Review of Economics of the Household, 2014. URL http://dx.doi.org/10.1007/s11150-014-9241-1.

J. van de Ven. A model of household savings and labour supply responses to the policy environment. Technical report, National Institute of Economic and Social Research, 2009.

O.E. Williamson. Transaction-cost economics: the governance of contractual relations. Journal of Law and Economics, 22(2):233-261, 1979.

X. Xiaohe and M.K. Whyte. Love matches and arranged marriages: A Chinese replication. Journal of Marriage and the Family, 52(3):709-722, 1990. 
Appendices 


\section{Chapter 1: Derivation of Best Responses of $i$ to $j$ playing}

$O, F$ or $W$

\section{Suppose $j$ plays $O$}

- state $I, i$ plays $S$ :

Agents will enter a cycle of alternating love such that total expected utility of $i$ is $U_{i, t}=\frac{(\beta+1)+\delta(2 \beta+1)}{1-\delta^{2}}$.

\begin{tabular}{cccccc}
\hline & $\alpha_{i, t}$ & $\alpha_{j, t}$ & $w_{i, t}$ & $w_{j, t}$ & $u_{i, t}$ \\
\hline $\mathrm{t}$ & 0 & 0 & 0 & 1 & $\beta+1$ \\
$\mathrm{t}+1$ & 1 & 0 & 1 & 0 & $2 \beta+1$ \\
$\mathrm{t}+2$ & 0 & 1 & 0 & 1 & $\beta+1$ \\
$\mathrm{t}+3$ & 1 & 0 & 1 & 0 & $2 \beta+1$ \\
\hline
\end{tabular}

- state $I, i$ plays $O$ :

Agents jump to the full love equilibrium within one period and total expected utility therefore is $U_{i, t}=2 \beta+\delta \frac{4 \beta}{1-\delta}$.

\begin{tabular}{cccccc}
\hline & $\alpha_{i, t}$ & $\alpha_{j, t}$ & $w_{i, t}$ & $w_{j, t}$ & $u_{i, t}$ \\
\hline $\mathrm{t}$ & 0 & 0 & 1 & 1 & $2 \beta$ \\
$\mathrm{t}+1$ & 1 & 1 & 1 & 1 & $4 \beta$ \\
$\mathrm{t}+2$ & 1 & 1 & 1 & 1 & $4 \beta$ \\
\hline
\end{tabular}

- state $I, i$ plays $F$ :

This leads the agents to the full love steady state, but takes longer than when $i$ plays $W$. Total expected utility is $U_{i, t}=(\beta+1)+\delta(2 \beta+1)+$ $\delta^{2} 2 \beta+\delta^{3} \frac{4 \beta}{1-\delta}$.

\begin{tabular}{cccccc}
\hline & $\alpha_{i, t}$ & $\alpha_{j, t}$ & $w_{i, t}$ & $w_{j, t}$ & $u_{i, t}$ \\
\hline $\mathrm{t}$ & 0 & 0 & 0 & 1 & $\beta+1$ \\
$\mathrm{t}+1$ & 1 & 0 & 1 & 0 & $2 \beta+1$ \\
$\mathrm{t}+2$ & 0 & 1 & 1 & 1 & $2 \beta$ \\
$\mathrm{t}+3$ & 1 & 1 & 1 & 1 & $4 \beta$ \\
\hline
\end{tabular}

- state $I, i$ plays $W$ :

This leads to the same situation as when $i$ plays $O$. 
- state $I I I, i$ plays $S$ :

The utility outcome is the same as in state $I$.

- state $I I I, i$ plays $O$ :

The outcome is the same as for strategy $S$.

- state $I I I, i$ plays $F$ :

The outcome is the same as for strategy $W$.

- state $I I I, i$ plays $W$ :

The utility outcome is the same as in state $I$.

We can now construct a strategy ranking. For state $I$ we have:

$$
\begin{gathered}
S \succ F \Leftrightarrow \frac{(\beta+1)+\delta(2 \beta+1)}{1-\delta^{2}}>(\beta+1)+\delta(2 \beta+1)+\delta^{2} 2 \beta+\delta^{3} \frac{4 \beta}{1-\delta} \Leftrightarrow \delta<\hat{\delta}_{B 1} \\
F \succ\{O, W\} \Leftrightarrow(\beta+1)+\delta(2 \beta+1)+\delta^{2} 2 \beta+\delta^{3} \frac{4 \beta}{1-\beta}>2 \beta+\delta \frac{4 \beta}{1-\delta} \Leftrightarrow \delta<\hat{\delta}_{B 2}=\hat{\delta}_{A 2}
\end{gathered}
$$

Where $\hat{\delta}_{B 1}=\frac{1-3 \beta}{2 \beta}+\sqrt{\left(\frac{1-3 \beta}{2 \beta}\right)^{2}+\frac{1-\beta}{\beta}}$. For state $I I I$ we have:

$$
\{S, O\} \succ\{F, W\} \Leftrightarrow \frac{(\beta+1)+\delta(2 \beta+1)}{1-\delta^{2}}>(\beta+1)+\delta(2 \beta+1)+\delta^{2} 2 \beta+\delta^{3} \frac{4 \beta}{1-\delta} \Leftrightarrow \delta<\hat{\delta}_{B 1} .
$$

\section{Suppose $j$ plays $F$}

- state $I, i$ plays $S$ :

The outcome is the same as when $j$ plays $S$ and $i$ plays $S$.

- state $I, i$ plays $O$ :

Here, within a couple of periods the agents reach the full love steady state, total expected utility is $U_{i, t}=\beta+\delta(1+\delta)+\delta^{2}(2 \beta+1)+\delta^{3} \frac{4 \beta}{1-\delta}$. 


\begin{tabular}{cccccc}
\hline & $\alpha_{i, t}$ & $\alpha_{j, t}$ & $w_{i, t}$ & $w_{j, t}$ & $u_{i, t}$ \\
\hline $\mathrm{t}$ & 0 & 0 & 1 & 0 & $\beta$ \\
$\mathrm{t}+1$ & 0 & 1 & 0 & 1 & $\beta+1$ \\
$\mathrm{t}+2$ & 1 & 0 & 1 & 1 & $2 \beta+1$ \\
$\mathrm{t}+3$ & 1 & 1 & 1 & 1 & $4 \beta$ \\
\hline
\end{tabular}

- state $I, i$ plays $F$ :

The outcome is the same as when $j$ plays $S$ and $i$ plays $S$.

- state $I, i$ plays $W$ :

The outcome is the same as when $j$ plays $S$ and $i$ plays $W$.

- state $I I I, i$ plays $S$ :

Agents go to the full love equilibrium in two steps and total expected utility therefore is $U_{i, t}=(\beta+1)+\delta(2 \beta+1)+\delta^{2} \frac{4 \beta}{1-\delta}$.

\begin{tabular}{cccccc}
\hline & $\alpha_{i, t}$ & $\alpha_{j, t}$ & $w_{i, t}$ & $w_{j, t}$ & $u_{i, t}$ \\
\hline $\mathrm{t}$ & 0 & 1 & 0 & 1 & $\beta+1$ \\
$\mathrm{t}+1$ & 1 & 0 & 1 & 1 & $2 \beta+1$ \\
$\mathrm{t}+2$ & 1 & 1 & 1 & 1 & $4 \beta$ \\
\hline
\end{tabular}

- state $I I I, i$ plays $O$ :

The outcome is the same as if $i$ played $S$.

- state $I I I, i$ plays $F$ :

The outcome is the same as when $j$ plays $S$ and $i$ plays $F$.

- state $I I I, i$ plays $W$ :

The outcome is the same as when $j$ plays $S$ and $i$ plays $W$.

The strategy ranking for state $I$ can be constructed in two steps:

$$
\begin{array}{r}
\{S, F\} \succ O \Leftrightarrow \frac{1}{1-\delta}>\beta+\delta(1+\delta)+\delta^{2}(2 \beta+1)+\delta^{3} \frac{4 \beta}{1-\delta} \Leftrightarrow \delta<\hat{\delta}_{C 1} \\
(3.19) \\
O \succ W \Leftrightarrow \beta+\delta(1+\delta)+\delta^{2}(2 \beta+1)+\delta^{3} \frac{4 \beta}{1-\delta}>\beta+\delta 2 \beta+\delta^{2} \frac{4 \beta}{1-\delta} \Leftrightarrow \delta<\hat{\delta}_{C 2}=\frac{1-\beta}{2 \beta-1}
\end{array}
$$


Where $\hat{\delta}_{C 1}$ cannot be determined analytically. It can be shown numerically, however, that $\hat{\delta}_{C 1}>\hat{\delta}_{B 1}$ for low levels of $\beta$ and the other way around for high levels and that $\hat{\delta}_{C 1}<\hat{\delta}_{A 1}$ for all levels of $\beta$.

For state $I I I$, the strategy ranking is the following:

$$
\{S, O\} \succ\{F, W\} \Leftrightarrow \beta+1+\delta(2 \beta+1)+\delta^{2} \frac{4 \beta}{1-\delta}>2 \beta+\delta \frac{4 \beta}{1-\delta} \Leftrightarrow \delta<\hat{\delta}_{C 3}=\hat{\delta}_{C 2} .
$$

\section{Suppose $j$ plays $W$}

- state $I, i$ plays $S$ :

Agents go to the full love equilibrium within two periods and total expected utility therefore is $U_{i, t}=\beta+1+\delta \frac{4 \beta}{1-\delta}$.

\begin{tabular}{cccccc}
\hline & $\alpha_{i, t}$ & $\alpha_{j, t}$ & $w_{i, t}$ & $w_{j, t}$ & $u_{i, t}$ \\
\hline $\mathrm{t}$ & 0 & 0 & 0 & 1 & $\beta+1$ \\
$\mathrm{t}+1$ & 1 & 0 & 1 & 1 & $4 \beta$ \\
$\mathrm{t}+2$ & 1 & 1 & 1 & 1 & $4 \beta$ \\
\hline
\end{tabular}

- state $I, i$ plays $O$ :

Agents jump to the full love equilibrium within one period and total expected utility therefore is $U_{i, t}=2 \beta+\delta \frac{4 \beta}{1-\delta}$.

\begin{tabular}{cccccc}
\hline & $\alpha_{i, t}$ & $\alpha_{j, t}$ & $w_{i, t}$ & $w_{j, t}$ & $u_{i, t}$ \\
\hline $\mathrm{t}$ & 0 & 0 & 1 & 1 & $2 \beta$ \\
$\mathrm{t}+1$ & 1 & 1 & 1 & 1 & $4 \beta$ \\
\hline
\end{tabular}

- state $I, i$ plays $F$ :

The outcome is the same as when $i$ plays $S$.

- state $I, i$ plays $W$ :

The outcome is the same as when $i$ plays $O$.

- state $I I I$ :

For strategies $S$ and $W$ the outcomes are the same as in state $I$. Here strategy $O$ is equivalent to $S$ and $F$ is equivalent to $W$. 
It is immediate that $\beta+1+\delta \frac{4 \beta}{1-\delta} \gtrless 2 \beta+\delta \frac{4 \beta}{1-\delta}$ can be reduced to $1>\beta$ which has been assumed. 